\title{
Estimating Bald Eagle Occupancy and Density in the Chesapeake Bay Watershed
}

\author{
Bethany Drahota
}

Follow this and additional works at: https://researchrepository.wvu.edu/etd

\section{Recommended Citation}

Drahota, Bethany, "Estimating Bald Eagle Occupancy and Density in the Chesapeake Bay Watershed" (2018). Graduate Theses, Dissertations, and Problem Reports. 5511.

https://researchrepository.wvu.edu/etd/5511

This Thesis is protected by copyright and/or related rights. It has been brought to you by the The Research Repository @ WVU with permission from the rights-holder(s). You are free to use this Thesis in any way that is permitted by the copyright and related rights legislation that applies to your use. For other uses you must obtain permission from the rights-holder(s) directly, unless additional rights are indicated by a Creative Commons license in the record and/ or on the work itself. This Thesis has been accepted for inclusion in WVU Graduate Theses, Dissertations, and Problem Reports collection by an authorized administrator of The Research Repository @ WVU. For more information, please contact researchrepository@mail.wvu.edu. 


\title{
Estimating Bald Eagle Occupancy and Density in the Chesapeake Bay Watershed
}

\author{
Bethany Drahota
}

Thesis submitted

to the

Davis College of Agriculture, Natural Resources and Design

at West Virginia University

in partial fulfillment of the requirements for the degree of

Master of Science

in

Wildlife and Fisheries Resources

James T. Anderson, Ph.D., Chair

Todd Katzner, Ph.D., Co-Chair

Adam Duerr, Ph.D.

Jeff Cooper

Division of Forestry and Natural Resources

Morgantown, West Virginia
2018

Keywords: bald eagle, density, Chesapeake Bay, Haliaeetus leucocephalus, mark-resight, occupancy, Poisson, presence-absence

Copyright 2018 Bethany Drahota 


\section{ABSTRACT \\ Estimating Bald Eagle Occupancy and Density in the Chesapeake Bay Watershed}

\section{Bethany Drahota}

Bald eagles (Haliaeetus leucocephalus) are a newly recovered species, and as such, little is known about their modern population dynamics and how these dynamics interact with their ecology. With the recent expansion of eagle populations, managers have begun to question assumptions about bald eagles, including their sensitivity to disturbances. Discerning how eagles react to both outside influences and internal factors is crucial for eagle conservation, especially in focal areas of importance, such as the Chesapeake Bay. I used seven years of monitoring data from the Virginia Department of Game and Inland Fisheries (VDGIF) to determine the occupancy (chapter 1) and density (chapter 2) of bald eagles in concentration areas in the Bay (Rappahannock, James, Potomac, York Rivers) and their associations with habitat characteristics. I used robust occupancy models to assess habitat associations within concentration areas (chapter 1). Additionally, I used Royle-Nichols n-mixture models to find average abundance and multiply this across the number of units in the study area to determine effective density (chapter 2). Bald eagle occupancy (chapter 1) was seasonally variable, with different covariates influencing eagles at different times of the year. Patterns of occupancy by non-breeding populations (summer months) responded to salinity, land cover, and recreational disturbance. Patterns of occupancy by bald eagles in winter (breeding season) responded to salinity and were age-specific. In both seasons, less saline waters (tidal fresh and oligohaline) were more frequently occupied than more saline waters (mesohaline). Density models (chapter 2) suggested that canopy cover may be important. However, the models I used appeared inappropriate for the data, they did not converge, and therefore my results were generally uninformative for this metric. Chapter one occupancy analyses show high rates of bald eagle occupancy and a relative resistance of eagles to recreational disturbances, which suggests that this population is growing, which may lead to increased management concerns in the future. Chapter two analyses revealed that archived data from mandated monitoring of sensitive species are valuable to the scientific community; however, if the models used are not appropriate for the data collected, the ability to answer research questions is limited. 


\section{TABLE OF CONTENTS}

\section{CHAPTER 1}

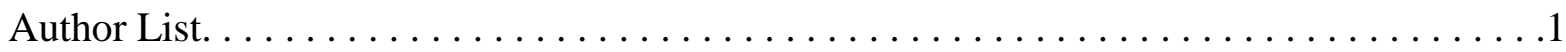

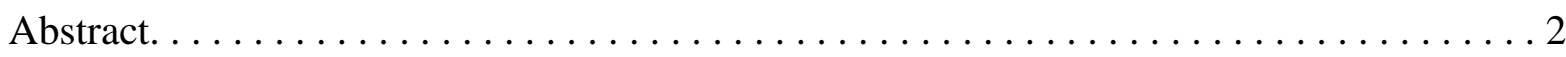

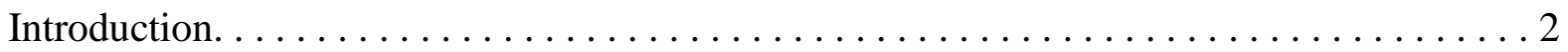

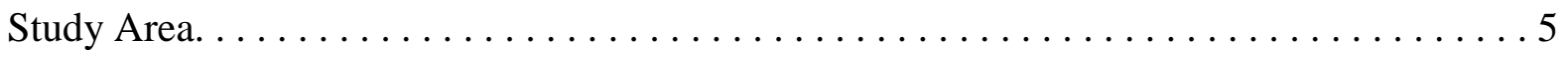

Methods. ..................................... 5

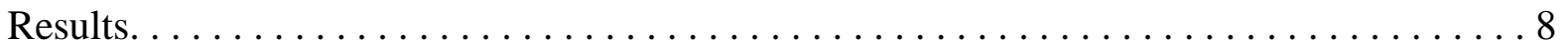

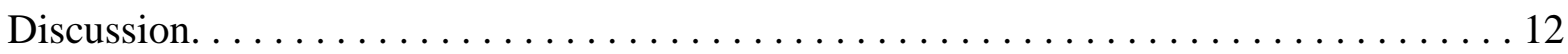

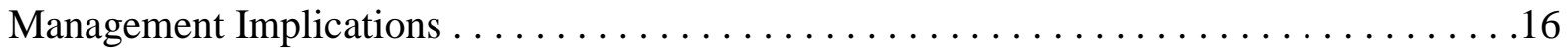

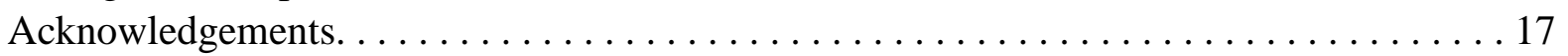

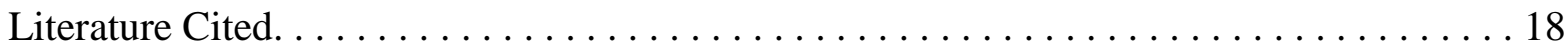

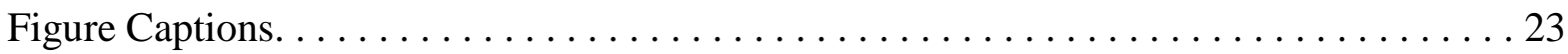

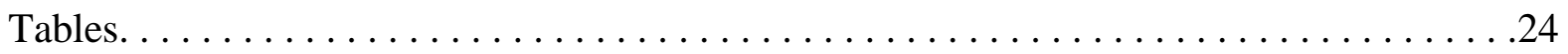

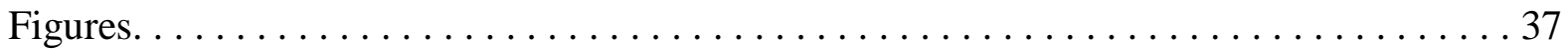

\section{CHAPTER 2}

Author List. . . . . . . . . . . . . . . . . . . . . . . . . . . . . . . . . . . . . 39

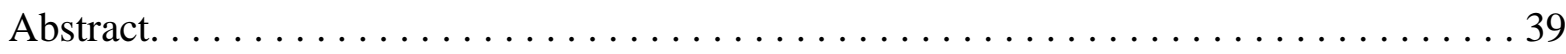

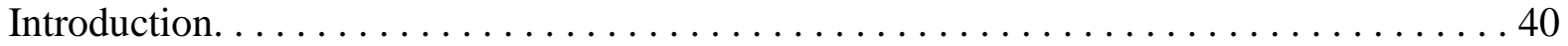

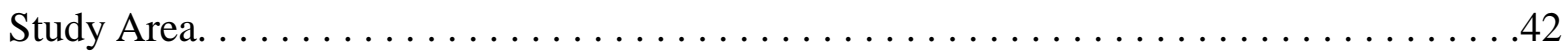

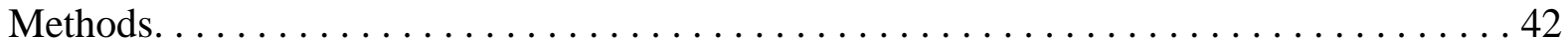

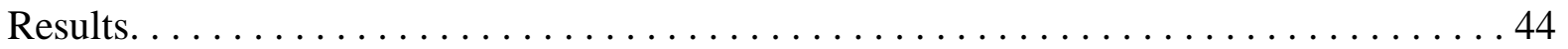

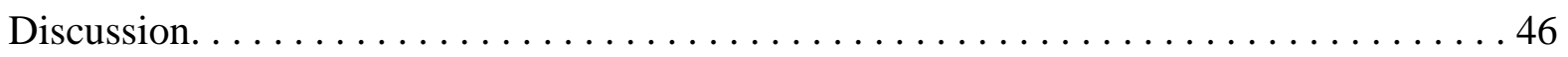

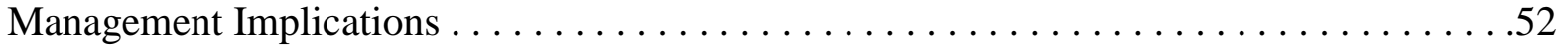

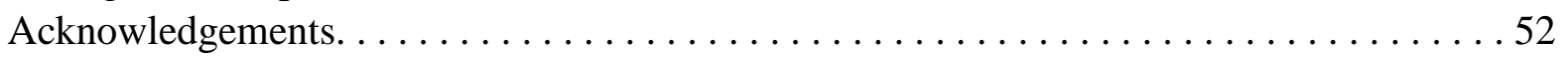

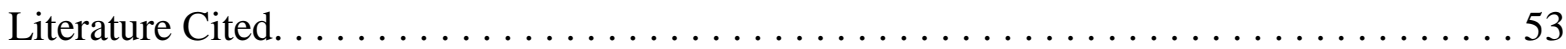

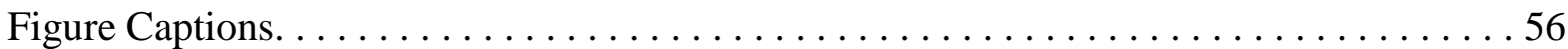

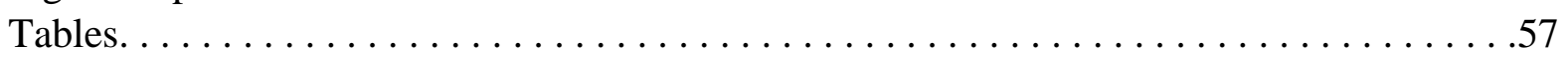

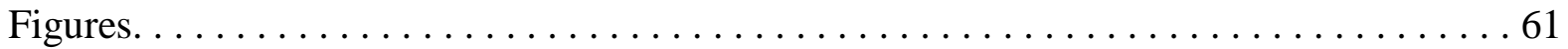


20 April 2018

Bethany Drahota

West Virginia University

$1472556^{\text {th }}$ Ave W

Edmonds, WA 98026

206-512-7852 (phone)

bdrahota@gmx.com

Drahota et al. • Estimating Bald Eagle Occupancy

Estimating Bald Eagle Occupancy in the Chesapeake Bay Watershed

BETHANY M. DRAHOTA ${ }^{1}$, Division of Forestry and Natural Resources, West Virginia

University, PO Box 6125, Morgantown, WV 26506 USA

ADAM DUERR ${ }^{2}$, Division of Forestry and Natural Resources, West Virginia University, PO

Box 6125, Morgantown, WV 26506 USA

JEFF L. COOPER, Virginia Department of Game and Inland Fisheries, 1320 Belman Road, Fredericksburg, VA 22401, USA

JAMES T. ANDERSON, Division of Forestry and Natural Resources, West Virginia University, PO Box 6125, Morgantown, WV 26506 USA

SERGIO HARDING, Virginia Department of Game and Inland Fisheries, 1320 Belman Road, Fredericksburg, VA 22401, USA

BRYAN D. WATTS, Center for Conservation Biology, College of William and Mary and Virginia Commonwealth University, PO Box 8795, Williamsburg, VA 23187 USA

TODD E. KATZNER, U.S. Geological Survey, Forest \& Rangeland Ecosystem Science Center, 970 Lusk Street, Boise, ID, 83706, USA

${ }^{1}$ Email: bdrahota@gmx.com

${ }^{2}$ Current address: Bloom Research, Inc. 1358 1/2 S Cloverdale Avenue, Los Angeles, CA USA 90019 
ABSTRACT Bald eagles (Haliaeetus leucocephalus) are a newly recovered species, and as such, little is known about their modern population dynamics and how these dynamics may be affecting their habitat ecology. With the recent expansion of eagle populations, managers have begun to question assumptions about bald eagles, including their sensitivity to disturbances. Discerning how individual eagles react to both outside influences and internal factors is crucial for eagle conservation considerations. The goal of this study was to determine the habitat associations and occupancy of bald eagles in concentration areas within the Chesapeake Bay (Rappahannock, James, Potomac, York Rivers). To achieve this goal, we analyzed survey data collected by the Virginia Department of Game and Inland Fisheries during 2006-2012 and we linked these data to a suite of intrinsic and extrinsic variables that could influence occupancy. Bald eagle occupancy was seasonally variable, with different covariates influencing eagles at different times of the year. Occupancy in the non-breeding season (summer months) was influenced by salinity, land cover, and recreational disturbance. Patterns of occupancy by bald eagles in winter (breeding season) responded to salinity type and were age-specific. In both seasons, lower saline waters (tidal fresh and oligohaline) had the highest occupancy rates. High occupancy of bald eagles in the Bay and a relative resistance of eagles to recreational disturbances suggests that this population is growing, which may lead to increased management concerns in the future.

KEY WORDS bald eagle (Haliaeetus leucocephalus), Chesapeake Bay, disturbance, markresight, occupancy, presence-absence, salinity.

Understanding species distributions across a landscape is essential to address management concerns and gain new insights into the ecology of species of concern (Sinclair et al. 2006). For many species of concern, legal requirements have mandated standardized surveys 
for monitoring purposes (USFWS 2007, USFWS 2013). However, because the primary purpose of this data collection is often to fulfill statutory requirements, these data are usually archived but not always analyzed. When available, the analysis of such stored data can provide detailed understanding of wildlife population dynamics and distributions to inform decision-making by wildlife managers.

Distributions of wildlife are often estimated using mark-recapture and resight analyses of individuals, techniques that may require meticulous adherence to survey protocols (Pollock 1982, Royle and Nichols 2003). However, a subset of existing analytical approaches does not have such strict requirements and can be readily applied to archived data that may have been originally collected for other purposes (MacKenzie et al. 2003). Occupancy models, for example, use presence and absence data to determine the probability of occupancy at a set of sites, and as such, they can be applied to a wide range of survey types. Consequently, these models have been used to estimate population dynamics or movements of many taxa, including ungulates (Duquette et al. 2014), lagomorphs (Eaton et al. 2014), insects (Ghara et al. 2014), and birds (Carillo-Rubio et al. 2014, Hill and Diefenbach 2014).

Bald eagles (Haliaeetus leucocephalus) have been the subject of more monitoring than most other species. The context for this monitoring lies in the unique conservation history of the species and the legal frameworks established for their protection. Bald eagle populations in North America were once extensive. However, dating back as far as the 1600s, populations of this species declined rapidly, most notably from persecution and organochlorine poisoning (Gerrard and Bortolotti 1988). By 1963 only 487 nesting pairs remained in the conterminous U.S. (USFWS 2013). After three decades of intensifying management, populations rebounded, and the bald eagle was removed from the U.S. Endangered Species List in 2007. As a component 
of their management and eventual delisting, extensive population monitoring has been either required or suggested by federal and state governments (USFWS 2007).

In eastern North America, some of the largest and most diverse bald eagle populations are found in the Chesapeake Bay. This important watershed hosts three distinct populations that visit at different times in their breeding cycle (Buehler et al. 1991, Watts et al. 2007). One group migrates from the North during winter, another from the South during summer, and a third population remains on in the Bay year-round. Insights into the dynamics of eagles in this watershed are of increasing importance as expanding numbers cause managers to shift their views on eagles from that of a species of concern to one that is abundant and sometimes even a nuisance.

The Virginia Department of Game and Inland Fisheries (VDGIF) and the College of William and Mary have, since 2006, surveyed eagle shoreline use along major tributaries in the Chesapeake Bay to identify winter and summer concentration areas. These data were collected by multiple observers with a diversity of methodologies, making traditional mark-recapture analysis, where birds must be individually marked to track unique histories, challenging. Therefore, to ascertain population dynamics of bald eagles in this area, we distilled archived survey data to presence and absence records and analyzed these data using an occupancy modeling framework. The specific objective of our study was to determine which environmental and population variables have the strongest effect on bald eagle occupancy along major rivers of the Chesapeake Bay. We evaluated patterns of occupancy as responses to eagle age, land use, water salinity, and recreational disturbance. 


\section{STUDY AREA}

The Chesapeake Bay (Figure 1) extends across three states (Maryland, Delaware, and Virginia), with its many tributaries spanning $>250-\mathrm{km}$, from New York to the Carolinas (Buehler et al. 1991). Shoreline areas within the Bay are highly varied and include mixed deciduous forested land, industrial land, and urban residential land (Thompson et al. 2005). Salinity in the Bay and its adjacent tributaries includes polyhaline (>18.0-30.0 parts per thousand (ppt)), mesohaline (>5.0-18.0 ppt), oligohaline (0.5-5.0 ppt), and tidal fresh (<0.5 ppt) (VIMS 2004). In the tributaries, fresher waters occur further inland and more saline waters occur closer to river mouths (Figure 2). The vegetation along the shoreline primarily consists of deciduous forest cover. Within the water, submerged aquatic vegetation is abundant. Taxa within the Bay include a variety of fish and bird populations, small mammals, amphibians, and raptors, including the bald eagle (Brown and Erdle 2009).

\section{METHODS}

\section{Data Collection}

We used bald eagle survey data collected on the Rappahannock, James, Potomac, and York rivers and their major tributaries. From 2006-2008 and 2011-2012 bald eagles were counted repeatedly on these rivers. Summer data included surveys from June, July, and August in 2006-2008 and 2011-2012. Winter included surveys from December, January, and February in 2006-2007, 2007-2008, 2010-2011, and 2011-2012. Timing of surveys was variable, with 1 to 2 per month completed for each river (Table 1).

Data were collected by boat by the VDGIF or by the Center for Conservation Biology (CCB) at the College of William and Mary. Boat surveys (Parker center console 182 with Yamaha 115hp outboard motor) utilized a field crew of at least two observers. Surveyors 
monitored one side of the shoreline on the outbound trip; on the return, they surveyed the other side. The boat moved approximately $15-20$ kilometers per hour (weather permitting) about 200$\mathrm{m}$ offshore, although distance from shoreline varied (as close as 50-m and sometimes greater than 300-m) depending on water depth, submerged vegetation, and obstacles. When an eagle was encountered, it was marked on 1:24,000 topographical maps with the help of a hand-held Geographic Positioning System device (Garmin 76 GPSmap '16) and aged into one of 7

classes - hatch year (Y), second year (S), third year (T), fourth year (F), adult (A), juvenile (subadult of unknown age) (J), or unknown (U). To understand how disturbance influenced eagles, surveyors also noted the presence and location of other boats encountered, and classified the activity of their occupants (working, recreating, or fishing). Finally, when people on shore were observed, surveyors noted their number, location, and activity as noted above.

\section{Data Classification}

We divided each river into individual river segments, or "units", using the "sampleperpointsalonglines" tool in the Geospatial Modeling Environment (v. 0.7.3.0 (Beyer 2012)) within ArcMap 10.2 (ESRI 2011). To do this, we created a line that followed the center of the river down its length and put a marker every $1-\mathrm{km}$ along this line. Then we extended each marker out 3-km to either side so that the river was broken up into $1-\mathrm{km}$ by $6-\mathrm{km}$ units down their entire lengths (405 units total). We assigned each boat, person, and eagle observation to a river unit using the point distance tool in ArcMap.

To understand habitat associations of eagles, we linked field survey data from each unit to the 2006 National Land Cover Database (NLCD; Fry et al. 2011). Further, survey data were linked to one of the salinity classes listed above, although the polyhaline salinity class was not used because no survey units occurred within polyhaline areas (VIMS 2004). We distilled land 
use and cover data into four main categories: developed, wetlands, open, and forest (deciduous, evergreen, and mixed cover). Within ArcMap, we calculated percent cover of land use and land cover in each river unit identified above. Because rivers are not static and tend to widen and narrow throughout their lengths, we evaluated land cover classes 3-km on either side from the river center line to account for these fluctuations.

Once eagles, habitat, and disturbance data were linked to river units, we imported data tables into Microsoft Excel (Redmond, WA) and, for each river unit, linked rows of presence or absence records for eagles to habitat and disturbance data for each river unit. These lines, or capture histories, included survey months and years as column headings, and each river unit included individual rows of data for each eagle age class. We created a capture history file for both summer and winter.

\section{Data Analysis}

For both summer (post-fledging) and winter (breeding) seasons, we used a single model set of robust occupancy models (Royle and Nichols 2003) within Program MARK (White and Burnham 1999), to estimate the effects of population and environmental variables on occupancy along the rivers we surveyed within the Chesapeake Bay. Our robust-design models included both primary and secondary sampling occasions. We delineated primary sampling occasions by year, where survey units could become occupied or unoccupied by eagles between each occasion (year). We chose secondary sampling occasions by month because these were likely to be demographically closed without changes in occupation in survey units within a season (year). Our models generated estimates for 4 parameters: probability of occupancy, probability of emigration, probability of colonization, and probability of detecting if a survey unit is occupied. Mark models use the terminology emigration and colonization in their outputs. In our case, these 
represent the probability of occupied river units becoming unoccupied (emigration) and the probability of unoccupied units becoming occupied (colonization). For the purposes of this paper, in discussing the results, we will refer to these parameters as emigration and colonization; in the discussion section we will refer to them within their biological context (e.g., discuss them in terms of becoming occupied or unoccupied). Our models gave us output estimates of occupancy probability by age class, of emigration and colonization among years, and of detection probabilities for each sampling month of each year (except for winter; see below).

We created 16 models for each season (Table 2). We modeled occupancy, emigration, and colonization parameters (as year-specific estimates) as functions of age, land use and cover, salinity, and disturbance covariates. We used Akaike's Information Criterion corrected for small sample size (AICc) to determine which of the competing models held the most support in the data for each season (Burnham and Anderson 2004). We modeled probability of detection as a response to age, forest cover, and disturbance (boats and people) for both seasons. We allowed detection to vary by each month of the year for summer models. However, because sample sizes for the winter season were smaller, we were unable to use this level of detail and instead allowed emigration, immigration, and detection to vary by year alone.

\section{RESULTS}

\section{Summary Statistics}

The data set we evaluated included a study area of 405 river units, of which 301 units were routinely sampled. Within these 301 units, 7,440 eagles were encountered, 5,277 in summer and 2,163 during winter. There was a total of 13 surveys in the winter season and 29 surveys in the summer season. Eagle encounters were highest in summer (18/unit, $\mathrm{SE}=0.90$ and 181/survey, $\mathrm{SE}=3.43$ ) and lowest in winter (7/unit; $\mathrm{SE}=0.32$ and 166/survey, $\mathrm{SE}=1.80$ ). Of units sampled, 
143 were in tidal fresh waters, 125 were in oligohaline, and 33 were in mesohaline areas. On average, observers counted 81 ( $\mathrm{SE}=2.50)$ eagles per survey in tidal fresh water in summer and 86 $(\mathrm{SE}=1.39)$ in winter. In oligohaline surveys, there were an average of $85(\mathrm{SE}=4.11)$ eagles in summer and $60(\mathrm{SE}=1.62)$ in winter. Mesohaline surveys held an average of $29(\mathrm{SE}=3.22)$ eagles in summer and $20(\mathrm{SE}=2.18)$ eagles in winter (Table 3).

For naïve estimates, we evaluated eagle encounters within land cover class by considering the number of eagles present where a land cover type held greater than $30 \%$ of the unit. Because there was some overlap in land cover among units, units could be represented in more than one cover type. Consequently, this evaluation included 333 units, with 6,199 eagle observations in summer and 2,571 in winter. During the summer season, eagles were counted primarily in deciduous cover, followed by open lands, wetlands, and developed lands. The cover types with the lowest number of eagles seen per unit were mixed forests, followed by evergreen forests. In winter, we recorded high eagle presence in developed lands, open lands, and deciduous tree cover. Wetlands also had higher numbers of eagles per unit, while evergreen cover held somewhat fewer eagle observations and mixed cover did not have any at all (Table 3).

During winter surveys, boats were observed in 57 units and people recorded in 25 . There was some overlap in river units here as boats and people could be observed either separately or together in the same unit. There were 502 eagles present in units with recreational boating presence, an average of 9 eagles per unit ( $\mathrm{SE}=1.11)$ and 39 per survey $(\mathrm{SE}=2.33)$. There were 228 eagle observations recorded in units with people, with an average of 9 eagles per humanoccupied unit ( $\mathrm{SE}=1.41)$ and 18 per survey ( $\mathrm{SE}=1.95)$. During the summer, 116 units had boating observations and 86 had people. There was a total of 2,655 eagles recorded in units with boats present and an average of 23 eagles per unit $(\mathrm{SE}=1.83)$ and 92 per survey $(\mathrm{SE}=3.66)$. Units 
with people had a total of 1,587 bald eagle observations, with an average of 18 eagles per unit $(\mathrm{SE}=2.05)$ and 55 per survey $(\mathrm{SE}=3.53)$. (Table 3$)$.

\section{Summer}

The top model for summer described emigration and colonization parameters as responses to fixed effects for salinity, land cover, and human disturbance (boats and people) (Table 4). Age was not a relevant factor in models for this season. Salinity, however, was a strongly influential variable, and was influential regardless of the effects of other environmental variables.

Bald eagles occupied primarily oligohaline and tidal fresh river segments. Segments of rivers with mesohaline salinity levels had lower probabilities of becoming occupied by eagles than did lower saline areas. Further, emigration from river units was least likely in oligohaline areas, then tidal fresh, and most likely in mesohaline waters. Additionally, emigration from river units slowly declined over time within all salinity types.

River units with deciduous tree cover were more likely to have bald eagles (tidal: 0.72 , $\mathrm{SE}=0.11$; oligohaline: $0.76, \mathrm{SE}=0.09$; mesohaline: $0.45, \mathrm{SE}=0.14)$, followed by those with evergreen (tidal: $0.27, \mathrm{SE}=0.15$; oligohaline: $0.31, \mathrm{SE}=0.17$; mesohaline: $0.10, \mathrm{SE}=0.08$ ), or mixed forest (tidal: 0.01, $\mathrm{SE}=0.02$; oligohaline: $0.02, \mathrm{SE}=0.03$; mesohaline: $0.004, \mathrm{SE}=0.007$ ) (Table 5). However, emigration from units was least likely in mixed forests, while colonization was more likely in evergreen and mixed forests than deciduous forests in tidal fresh (Table 6), oligohaline (Table 7), and mesohaline waters (Table 8). Additionally, units with evergreen forests were likely to be colonized, to become unoccupied, and to become occupied at low rates, regardless of salinity class. 
Bald eagles had a high probability of occupancy in wetland land cover. Occupancy was similar between oligohaline $(0.84, \mathrm{SE}=0.07)$ and tidal fresh waters $(0.81, \mathrm{SE}=0.08)$, with lower rates in mesohaline waters $(0.57, \mathrm{SE}=0.12)$. Probabilities of emigration from within wetland landscapes were consistently low over time and colonization of these areas was likewise rare. Further, there were low emigration rates where development was present (range $0.00-0.07$ ) in fresh (Table 6), oligohaline (Table 7), and mesohaline (Table 8). However, the effects of development on colonization, were more varied. In some years, development meant a bald eagle was more likely to move into a river unit and in other years development had the opposite effect. Further, developed areas had varying rates of eagle occupancy, but followed previous trends in salinity, with oligohaline units having higher occupancy than both tidal fresh and mesohaline units (range $0.21-0.50$; Table 5).

Human disturbance positively influenced eagle site selection and did not appear to impact whether bald eagles left a river unit. Eagles were more likely to be found in areas with some disturbance present, although units with boats were used more than units with people (Table 5).

\section{Winter}

The top model for eagles in winter with the strongest support in the data had fixed effects for age, salinity, and disturbance (Table 4). However, the number of boat and people observed during this season were markedly low and the beta estimates for this sub-model were likewise low, meaning the disturbance variable did not have a biological effect. Considering this, and the small difference in AICc (Table 4) between the first and second models, we decided to evaluate the second model with fixed effects for age and salinity only. Occupancy estimates were highest in oligohaline waters, followed by tidal fresh, and then mesohaline. That said, during winter, 
eagles were present in all salinity levels surveyed and movement rates from river units of all salinity levels were comparable.

Of all age classes during winter, subadult birds had the highest probability of occupancy regardless of salinity class (tidal: $0.49, \mathrm{SE}=0.07$; oligohaline: $0.58, \mathrm{SE}=0.07$; mesohaline: 0.31 , $\mathrm{SE}=0.12$ ). Occupancy probability was intermediate for adults (tidal: $0.43, \mathrm{SE}=0.04$; oligohaline: 0.52, $\mathrm{SE}=0.04$; mesohaline: $0.26, \mathrm{SE}=0.09$ ) and lowest for hatch year birds (tidal: $0.40, \mathrm{SE}=0.11$; oligohaline: $0.49, \mathrm{SE}=0.11$; mesohaline: $0.24, \mathrm{SE}=0.12$ ). Emigration rates were lower for adult birds than they were for all other age classes, regardless of salinity class. Hatch year birds and subadult eagles had comparable emigration rates always between 25 and 29\% (Table 9). Colonization was higher for hatch year birds, followed by subadults, then adults. Adult eagles had the lowest probability of both emigration and colonization of river units within all salinity classes, while hatch year birds had the highest.

\section{DISCUSSION}

Our analysis illustrates how archived data collected for other purposes can, in some cases, be used to gain insight into the movements and habitat associations of high priority wildlife populations. The data we considered illustrate the relationships between eagles and the landscape they occupy. They also demonstrate that some of the historical ideas about bald eagle behavior, especially regarding their associations with human activity (Knight and Knight 1984, Fraser et al. 1985), may not apply in this era of high-density bald eagle populations.

As a newly recovered species, bald eagles are particularly interesting to management agencies, especially in areas that attract large numbers of eagles each year. The Chesapeake Bay is the largest estuary in the United States and is a well-known area of convergence for 3 different breeding and migratory bald eagle populations (Mojica 2006, Watts et al. 2007). These unusual 
patterns present both unique challenges and unique benefits to understanding occupancy in this situation.

\section{Summer}

In our study, salinity was a primary driver of eagle occupancy. As transitional ecosystems, estuaries such as the Bay host a wide range of salinity types, often with multiple types within a short distance. Salinity is widely known as a primary driver of processes within these systems, including influencing the distribution of aquatic inhabitants, such as the fish species that bald eagles prey upon (Watts et al. 2006, 2007). During summer, we found the highest proportions of eagles in tidal fresh and oligohaline areas. This result is in keeping with previous studies, where eagles were found more commonly near tidal fresh shorelines, perhaps because of the fish species present in these areas (Watts et al. 2007, Markham and Watts 2008). Prey density has been suggested as the main driver of eagle nesting densities (Swenson et al. 1986, Hansen 1987) and fisheries located in lower saline waters are a likely cause for the influence salinity has on eagle presence (Watts et al. 2006). Additionally, seasonal fish spawning is a factor in eagle behavior. In our study area, there are spring spawning runs of anadromous Clupeidae (shad and herring), as well as resident catfish (Ictaluridae spp.; Pylodictis olivaris and Ictalurus furcatus).

Patterns in land cover, as well as salinity, also influenced occupancy probability. Eagles particularly used areas with deciduous tree cover and wetland areas, especially in combination with lower saline waters. Wetlands had higher proportions of bald eagle occupancy than forested areas, suggesting their relative importance to eagles. As wetlands are often nearer open water areas and house many different fish and waterbird populations, they are likely utilized as foraging spaces, while forested areas are used for perching and nesting. 
Developed lands and human recreational disturbances influenced bald eagle use in the Chesapeake Bay. This finding was consistent with past studies demonstrating that anthropogenic features (housing units, factories, etc.) are often detrimental to eagles (Stalmaster and Newman 1978, Buehler et al. 1991, Chandler et al. 1995, Stokstad 2007). Recreational disturbances, such as boaters and pedestrians have likewise negatively influenced bald eagle use of the landscape (Andrew and Mosher 1982, Buehler et al. 1991, Buehler et al. 1992, Chandler et al. 1995, Watts and Whalen 1997, Brown and Erdle 2009, Saalfeld and Conway 2010). However, in contrast to previously reported trends, we found that bald eagle responses to disturbances and development were variable and not always negative. In our study, the probability of units becoming occupied in developed areas differed by year, but was not strongly unlikely, and the effects of human recreation on eagle occupancy were not markedly negative. Additionally, we found that the highest rates of bald eagle occupancy occurred in oligohaline waters, followed by tidal fresh and mesohaline waters, regardless of the land cover type present, including developed areas. This trend in occupancy across cover types leads us to conclude that development may not be as strong a deterrent as previously determined. Moreover, responses to recreational disturbance were atypical, with bald eagle use and recreational disturbances occurring in the same areas. This outcome may be linked to salinity associations with eagles, where both humans and eagles focus on similar prey items. Additionally, these variable associations may be an effect of growing eagle densities; with populations increasing and suitable habitat remaining static or decreasing, eagles may be forced to become more tolerant of urban areas.

Within the summer season, the only variable we modeled that was not strongly influential was age structure. This was notable, as previous research found that there were specific age classes of bald eagles known to occupy the Chesapeake Bay, particularly subadult eagles (Watts 
et al. 2007). However, while multiple age classes are present in both seasons, breeding bald eagles (in winter) are more territorial than they would be in the non-breeding season (summer), and therefore, it is reasonable that age would not be as impactful in the summer post-fledging season. Instead, they are more influenced by the cover type itself during this time.

\section{Winter}

The winter model with the best support in the data included parameters describing salinity and age structure influences on eagle site occupancy. We found that subadult birds were more likely than birds of any other age class to occupy river units. This is consistent with past research showing that the Chesapeake Bay is a winter convergence area for subadult bald eagles (Watts et al. 2007). Age also influenced movement between units, or the probability of a site becoming unoccupied (extinction rates). The value of this parameter was low for adult eagles, suggesting that they are less inclined to leave an already occupied site. As this is the breeding season in the Bay, bald eagles are likely remaining in set territories near their nest sites. This tendency of adults to stay in specific areas also may be a result of space limitations. Hatch year and subadult bald eagles did not commonly abandon river units, although they did so with more regularity than adults. This could be a result of being excluded from river units near more established birds.

In addition to age, and comparable to summer, salinity strongly influenced bald eagle occupancy during winter. Eagles were found in tidal fresh and oligohaline (low salinity) waters more commonly than mesohaline waters, and there were no occupied units in polyhaline waters within our study area. This link to low salinity waters may be a result of prey concentration areas (Markham and Watts 2008). In the winter, bald eagles split their prey focus and hunt both fish 
(primary summer prey) and waterbirds, which migrate to the Bay in winter (Markham 2004, Watts et al. 2007).

Our best model in winter included far fewer environmental variables than we saw during the summer season. This was a surprising finding that may inform about eagle ecology during breeding and nesting times. In winter, age structure was influential where it was not in summer, and neither land cover nor recreational disturbance were important. This lack of influence may be due to breeding bald eagles' drive to find and occupy areas with high prey densities, to the exclusion of most else, in order to feed nestlings. Additionally, the lack of age as a driving force in the summer season is indicative of a lack of territoriality in post-fledging eagles, while territoriality was high in the winter breeding season, and therefore, age was an important factor in bald eagle occupancy. These findings may inform future management activities in winter in that they imply a need to focus on prey management during the winter season, rather than land cover alterations.

\section{MANAGEMENT IMPLICATIONS}

As apex predators, bald eagles play an important role in ecosystems and they interact with humans in many ways, often sharing spaces (Harvey et al. 2012). A surprising outcome of our study was that bald eagles only sometimes showed a negative response to human disturbance. This finding is concordant with earlier work done with this species (Andrew and Mosher 1982, Watts et al. 2006), suggesting that as bald eagle populations increase, individuals may be forced to adapt to human influences in their environment. The implications of our work include the importance of continued monitoring of bald eagle responses to increasing development, as well as managing for habitat in lower saline areas, with a focus on the fish, waterbird, and waterfowl populations therein. Further, both wetlands and deciduous cover types 
were favored by bald eagles during summer and may be important areas to manage for foraging and nesting purposes.

\section{ACKNOWLEDGMENTS}

We thank the many individuals and organizations who contributed and supported this project including: Tricia Miller (Conservation Science Global, Inc.) and C. Markham (College of William and Mary). We also thank the organizations that collected much of the data that were analyzed within this project including: The Virginia Department of Game and Inland Fisheries and The College of William and Mary (Virginia Commonwealth University). J. A. was supported by the National Science Foundation under Cooperative Agreement OIA-1458952 and by the USDA National Institute of Food and Agriculture, McIntire Stennis project WVA00117 during manuscript preparation. Any use of trade, product, or firm names is for descriptive purposes only and does not imply endorsement by the U.S. Government. This is Scientific Article number XXXX of the West Virginia University Agricultural and Forestry Experiment Station, Morgantown. 


\section{LITERATURE CITED}

Andrew, J. M., and J. A. Mosher. 1982. Bald eagle nest site selection and nesting habitat in Maryland. The Journal of Wildlife Management 46:383-390.

Beyer, H. L. 2012. Geospatial modelling environment (Version 0.7.3.0). (Software). <http://www.spatialecology.com/gme>. Accessed 15 January 2014.

Brown, J., and S. Erdle. 2009. Amphibians, reptiles, birds, and mammals of the York River. Journal of Coastal Research SI(37): 111-117.

Buehler, D. A., T. J. Mersmann, and J. D. Fraser. 1991. Differences in distribution of breeding, nonbreeding, and migrant bald eagles on the Northern Chesapeake Bay. The Condor 93:399-408.

Buehler, D. A., S. K. Chandler, T. J. Mersmann, J. D. Fraser, and J. K. D. Seegar. 1992. Nonbreeding bald eagle perch habitat on the Northern Chesapeake Bay. The Wilson Bulletin 104:540-545.

Burnham, K. P., and D. R. Anderson. 2004. Multimodel inference: Understanding AIC and BIC in model selection. Sociological Methods and Research 33:261-304.

Carrillo-Rubio, E., M. Kéry, S. J. Morreale, P. J. Sullivan, B. Gardner, E. G. Cooch, and J. P. Lassoie. 2014. Use of multispecies occupancy models to evaluate the response of bird communities to forest degradation associated with logging. Conservation Biology 28:1034-1044.

Chandler, S. K., J. D. Fraser, D. A. Buehler, and J. K. Seegar. 1995. Perch trees and shoreline development as predictors of bald eagle distribution on Chesapeake Bay. The Journal of Wildlife Management 59:325-332. 
Duquette, J. F., J. L. Belant, N. J. Svoboda, D. E. Beyer Jr., and C. A. Albright. 2014. Comparison of occupancy modeling and radiotelemetry to estimate ungulate population dynamics. Population Ecology 56:481-492.

Eaton, M. J., P. T. Hughes, J. E. Hines, J. D. Nichols. 2014. Testing metapopulation concepts: effects of patch characteristics and neighborhood occupancy on the dynamics of an endangered lagomorph. Oikos 123:662-676.

ESRI 2011. ArcGIS Desktop. Environmental Systems Research Institute, Release 10. Redlands, CA.

Fraser, J. D., L. D. Frenzel, and J. E. Mathisen. 1985. The impact of human activities on breeding bald eagles in north-central Minnesota. The Journal of Wildlife Management 49: 585-592.

Fry, J., G. Xian, S. Jin, J. Dewitz, C. Homer, L. Yang, C. Barnes, N. Herold, and J. Whickham. 2011. Completion of the 2006 National Land Cover Database for the conterminous United States. Photogrammatic Engineering and Remote Sensing, 77:858-864.

Gerrard, J. M, and G. R. Bortolotti. 1988. The bald eagle: haunts and habits of a wilderness monarch. Smithsonian Institution Press, Washington, DC, USA.

Ghara, M., Y. Ranganathan, A. Krishnan, V. Gowda, and R. M. Borges. 2014. Divvying up an incubator: how parasitic and mutualistic fig wasps use space within their nursery microcosm. Arthropod-Plant Interactions 8:191-203.

Hansen, A. J. 1987. Regulation of bald eagle reproductive rates in southeast Alaska. Ecology 68: $1387-1392$. 
Harvey, C. J., T. P. Good, and S. F. Pearson. 2012. Top-down influence of resident and overwintering bald eagles (Haliaeetus leucocephalus) in a model marine ecosystem. Canadian Journal of Zoology 90:903-914.

Hill, J. M., and D. R. Diefenbach. 2014. Occupancy patterns of regionally declining grassland sparrow populations in a forested Pennsylvania landscape. Conservation Biology 28:735744.

Knight, R. L. and Knight, S. K. 1984. Responses of wintering bald eagles to boating activity. The Journal of Wildlife Management 48:999-1004.

MacKenzie, D. I., J. D. Nichols, J. E. Hines, M. G. Knutson, and A. B. Franklin. 2003. Estimating site occupancy, colonization, and local extinction when a species is detected imperfectly. Ecology 84:2200-2207.

Markham, A. C. 2004. The influence of salinity on diet composition, provisioning patterns, and nestling growth in bald eagles in the lower Chesapeake Bay. M.A. thesis, College of William and Mary, Williamsburg, VA.

Markham, A. C., and B. D. Watts. 2008. The influence of salinity on the diet of nesting bald eagles. Journal of Raptor Research 42:99-109.

Mojica, E. K. 2006. Migration, home range, and important use areas of Florida sub-adult bald eagles. M.S. thesis, University of Georgia, Athens, GA.

Pollock, K. H. 1982. A capture-recapture design robust to unequal probability of capture. The Journal of Wildlife Management 46:752-757.

Royle, J. A., and J. D. Nichols. 2003. Estimating abundance from repeated presence-absence data or point counts. Ecology 84:777-790. 
Saalfeld, S. T., and W. C. Conway. 2010. Local and landscape habitat selection of nesting bald eagles in east Texas. Southeastern Naturalist 9:731-742.

Sinclair, A. R. E., J. M. Fryxell, and G. Caughley. 2006. Wildlife ecology, conservation and management. Second edition. Wiley-Blackwell, Malden, MA.

Stalmaster, M. V., and J. R. Newman. 1978. Behavioral responses of wintering bald eagles to human activity. The Journal of Wildlife Management 42:506-513.

Stokstad, E. 2007. Can the bald eagle still soar after it is delisted? Science 316:1689-1690.

Swenson, J. E., K. L. Alt, and R. L. Eng. 1986. Ecology of bald eagles in the greater Yellowstone ecosystem. Wildlife Monographs 95:3-46.

Thompson, C. M., P. E. Nye, G. A. Schmidt, and D. K. Garcelon. 2005. Foraging ecology of bald eagles in a freshwater tidal system. The Journal of Wildlife Management 69:609617.

U.S. Fish \& Wildlife Service (USFWS). 2007. National bald eagle management guidelines. <https://www.fws.gov/northeast/ecologicalservices/eaglenationalguide.html>. Accessed 30 March 2018.

U.S. Fish \& Wildlife Service (USFWS). 2013. Bald eagle fact sheet: natural history, ecology, and history of recovery. 〈http://www.fws.gov/midwest/eagle/recovery/biologue.html>. Accessed 13 January 2014.

Virginia Institute of Marine Science (VIMS). 2004. ChesMMAP bottom salinity. <http://www.arcgis.com/apps/Viewer/index.html?appid=8897fdb6714d44cc903e75b561 4709a9>. Accessed 13 October 2013. 
Watts, B. D., and D. M. Whalen. 1997. Interactions between eagles and humans in the James River bald eagle concentration area. Center for Conservation Biology Technical Report, CCBTR-97-02, College of William and Mary, Williamsburg, VA.

Watts, B. D., A. C. Markham, and M. A. Byrd. 2006. Salinity and population parameters of bald eagles (Haliaeetus leucocephalus) in the lower Chesapeake Bay. The Auk 123:393-404.

Watts, B. D., G. D. Therres, and M. A. Byrd. 2007. Status, distribution, and the future of bald eagles in the Chesapeake Bay area. Waterbirds 30(special publication):25-38.

White, G. C., and K. P. Burnham. 1999. Program MARK: Survival estimation from populations of marked animals. Bird Study 46(Supplement):120-138. 


\section{FIGURE CAPTIONS}

Figure 1. Map showing the location of the primary study area within the Chesapeake Bay region of Virginia, USA, where bald eagles were observed and counted (study period 2006-2012). Map also shows locations of bald eagle observations (counts) within the study area (grey dots) as well as an inset of the United States highlighting the study area within a black circle.

Figure 2. Map showing the salinity class breakdown covering the study area within the Chesapeake Bay region of Virginia, USA. 


\section{TABLES}

Table 1. This table shows the number of surveys conducted along the James, Rappahannock, York, and Potomac Rivers from 2006 to 2012 in the Chesapeake Bay. 'Entire River' is a reference to if the survey was conducted all the way to the mouth of the Bay (Y) or only focused on the inland areas $(\mathrm{N})$.

\begin{tabular}{llll}
\hline River & Year & No.\# Surveys & Entire River (Y/N) \\
\hline James & 2006 & 2 & N-Close to mouth \\
& 2011 & 3 & $\mathrm{~N}$ \\
York & 2012 & 2 & $\mathrm{~N}$ \\
Rappahannock & 2006 & 2 & $\mathrm{~N}$ (tributaries) \\
& 2006 & 2 & $\mathrm{~N}$ \\
& 2007 & 7 & $\mathrm{~N}$ \\
& 2008 & 5 & $\mathrm{~N}$ \\
Potomac & 2011 & 2 & $\mathrm{~N}$ \\
& 2012 & 3 & $\mathrm{~N}$ \\
& 2006 & 8 & $\mathrm{~N}$ \\
& 2007 & 9 & $\mathrm{~N}$ \\
& 2008 & 4 & $\mathrm{~N}$ \\
& 2011 & 1 & $\mathrm{~N}$ \\
\hline
\end{tabular}


Table 2. A key to the model set showing the 16 individual models that were created to test for the effects of intrinsic (age) and extrinsic (environmental) variables on bald eagle occupancy in the Virginia region of the Chesapeake Bay from 2006 to 2012. Occupancy, emigration, and colonization parameters were all varied by the same factors within a model. The detection parameter varied by forest cover and disturbance in every model, and because of that, this parameter is not shown in the table below.

\begin{tabular}{lc}
\hline Occupancy, Emigration, \& Colonization Parameters & Model Number \\
\hline Age, Salinity, Land Cover, Disturbance & 1 \\
Age, Salinity, Land Cover & 2 \\
Age, Land Cover, Disturbance & 3 \\
Age, Salinity, Disturbance & 4 \\
Salinity, Land Cover, Disturbance & 5 \\
Salinity, Disturbance & 6 \\
Salinity, Land Cover & 7 \\
Age, Disturbance & 8 \\
Age, Land Cover & 9 \\
Age, Salinity & 10 \\
Land Cover, Disturbance & 11 \\
Age & 12 \\
Salinity & 13 \\
Land Cover & 14 \\
Disturbance & 15 \\
Null & 16 \\
\hline
\end{tabular}


Table 3. Summary statistics from both summer and winter datasets of bald eagles in the

Chesapeake Bay from 2006 to 2012. Values calculated below include the overall average number of eagles per river unit as well as the average number of eagles seen per survey. Values are also shown for the number of eagles per unit (Avg./Ut.) and per survey (Avg./Survey) based on different salinity and land use values. Values are calculated for each season and include their corresponding standard errors (SE).

\begin{tabular}{|c|c|c|c|c|c|c|c|c|}
\hline \multirow[b]{3}{*}{ Variable } & \multicolumn{8}{|c|}{ Season } \\
\hline & \multicolumn{4}{|c|}{ Summer } & \multicolumn{4}{|c|}{ Winter } \\
\hline & Avg./Ut. & $\mathrm{SE}$ & Avg./Survey & $\mathrm{SE}$ & Avg./Ut. & $\mathrm{SE}$ & Avg./Survey & $\mathrm{SE}$ \\
\hline Overall & 17.532 & 0.896 & 181.966 & 3.344 & 7.186 & 0.323 & 166.384 & 1.801 \\
\hline Tidal Fresh & 16.476 & 1.127 & 81.241 & 2.503 & 7.846 & 7.846 & 86.308 & 1.387 \\
\hline Oligohaline & 19.648 & 1.979 & 84.690 & 4.108 & 6.272 & 0.522 & 60.308 & 1.618 \\
\hline Mesohaline & 14.091 & 3.023 & 16.034 & 3.225 & 7.788 & 1.367 & 19.769 & 2.178 \\
\hline Developed & 14.034 & 2.208 & 14.034 & 2.208 & 8.655 & 1.686 & 19.308 & 2.518 \\
\hline Wetlands & 15.720 & 1.976 & 44.448 & 3.323 & 7.293 & 0.810 & 46.000 & 2.034 \\
\hline Open & 19.270 & 1.949 & 66.448 & 3.619 & 7.590 & 0.552 & 58.385 & 1.531 \\
\hline Deciduous & 22.440 & 1.870 & 84.345 & 3.625 & 8.349 & 0.642 & 6.706 & 1.860 \\
\hline Evergreen & 11.455 & 2.708 & 4.345 & 1.668 & 4.818 & 1.757 & 4.077 & 1.616 \\
\hline Mixed Tree & 2.000 & 0.000 & 0.138 & 0.000 & 0.000 & 0.000 & 0.000 & 0.000 \\
\hline Boats & 22.888 & 1.832 & 91.551 & 3.663 & 8.807 & 1.115 & 38.615 & 2.334 \\
\hline People & 18.453 & 2.050 & 54.724 & 3.531 & 9.120 & 1.409 & 17.538 & 1.953 \\
\hline
\end{tabular}


Table 4. Estimates for changes in Akaike's Information Criterion (AICc) between the top three models of best fit for bald eagles in each season (2006 to 2012) in the Chesapeake Bay and the weights of each model.

\begin{tabular}{|c|c|c|c|c|}
\hline Season & Occupancy, Emigration, Colonization & Detection & $\triangle \mathrm{AICc}$ & Weight \\
\hline \multirow[t]{3}{*}{ Summer } & salinity, land cover, disturbance & disturbance, forest cover & 0.000 & 0.995 \\
\hline & age, salinity, land cover & disturbance, forest cover & 10.474 & 0.005 \\
\hline & salinity, disturbance & disturbance, forest cover & 20.927 & $<0.001$ \\
\hline \multirow[t]{3}{*}{ Winter } & age, salinity, disturbance & disturbance, forest cover & 0.000 & 0.521 \\
\hline & age, salinity & disturbance, forest cover & 0.189 & 0.474 \\
\hline & age, salinity, land cover & disturbance, forest cover & 9.461 & 0.005 \\
\hline
\end{tabular}


Table 5. Summer estimates of probabilities of occupancy and their associated standard errors (SE) for each environmental variable within each salinity class. These results show the probabilities of bald eagles occupying certain areas of the landscape in the Chesapeake Bay (2006 to 2012) given the salinity present in the summer season. Probabilities of eagles occupying river units with boats and/or people present were calculated in both deciduous and developed cover to inform on occupancy likelihoods in different cover types.

\begin{tabular}{|c|c|c|c|c|c|c|}
\hline \multirow[b]{3}{*}{ Variable } & \multicolumn{6}{|c|}{ Salinity } \\
\hline & \multicolumn{2}{|c|}{ Tidal Fresh } & \multicolumn{2}{|c|}{ Oligohaline } & \multicolumn{2}{|c|}{ Mesohaline } \\
\hline & Probability & $\mathrm{SE}$ & Probability & $\mathrm{SE}$ & Probability & SE \\
\hline Developed & 0.446 & 0.123 & 0.503 & 0.134 & 0.206 & 0.086 \\
\hline Wetlands & 0.806 & 0.076 & 0.840 & 0.066 & 0.573 & 0.119 \\
\hline Deciduous & 0.718 & 0.105 & 0.763 & 0.088 & 0.451 & 0.140 \\
\hline Evergreen & 0.266 & 0.151 & 0.314 & 0.174 & 0.105 & 0.076 \\
\hline Mixed Forest & 0.015 & 0.021 & 0.019 & 0.026 & 0.005 & 0.007 \\
\hline Other & 0.681 & 0.100 & 0.729 & 0.096 & 0.408 & 0.108 \\
\hline Boats (in developed) & 0.754 & 0.102 & 0.795 & 0.096 & 0.497 & 0.139 \\
\hline Boats (in deciduous) & 0.907 & 0.042 & 0.925 & 0.032 & 0.758 & 0.096 \\
\hline People (in developed) & 0.535 & 0.122 & 0.593 & 0.126 & 0.271 & 0.102 \\
\hline People (in deciduous) & 0.785 & 0.093 & 0.822 & 0.075 & 0.541 & 0.147 \\
\hline
\end{tabular}


Table 6. Summer estimates of the probabilities of bald eagle emigration and colonization in the Chesapeake Bay from 2006 to 2012 (standard errors (SE)) in tidal fresh waters, within different land cover types between study years.

\begin{tabular}{|c|c|c|c|c|c|}
\hline \multirow[b]{2}{*}{ Variable } & \multirow[b]{2}{*}{ Year } & \multicolumn{2}{|c|}{ Emigration } & \multicolumn{2}{|c|}{ Colonization } \\
\hline & & Probability & $\mathrm{SE}$ & Probability & $\mathrm{SE}$ \\
\hline \multirow[t]{4}{*}{ Developed } & $2006-07$ & 0.054 & 0.100 & 0.180 & 0.237 \\
\hline & $2007-08$ & 0.055 & 0.090 & 0.094 & 0.145 \\
\hline & $2008-11$ & $<0.001$ & $<0.001$ & 0.042 & 0.079 \\
\hline & 2011-12 & 0.004 & 0.015 & 0.079 & 0.139 \\
\hline \multirow[t]{4}{*}{ Wetlands } & 2006-07 & 0.074 & 0.096 & $<0.001$ & 0.001 \\
\hline & $2007-08$ & 0.075 & 0.101 & $<0.001$ & $<0.001$ \\
\hline & 2008-11 & $<0.001$ & $<0.001$ & $<0.001$ & $<0.001$ \\
\hline & 2011-12 & 0.005 & 0.012 & $<0.001$ & $<0.001$ \\
\hline \multirow{4}{*}{ Deciduous } & 2006-07 & 0.745 & 0.329 & $<0.001$ & 0.002 \\
\hline & 2007-08 & 0.746 & 0.279 & $<0.001$ & $<0.001$ \\
\hline & $2008-11$ & $<0.001$ & $<0.001$ & $<0.001$ & $<0.001$ \\
\hline & 2011-12 & 0.155 & 0.549 & $<0.001$ & $<0.001$ \\
\hline \multirow[t]{4}{*}{ Evergreen } & 2006-07 & 0.973 & 0.115 & 1.000 & $<0.001$ \\
\hline & $2007-08$ & 0.973 & 0.117 & 1.000 & $<0.001$ \\
\hline & 2008-11 & $<0.001$ & $<0.001$ & 1.000 & $<0.001$ \\
\hline & $2011-12$ & 0.690 & 1.188 & 1.000 & $<0.001$ \\
\hline \multirow[t]{4}{*}{ Mixed Forest } & 2006-07 & 0.013 & 0.080 & 0.999 & $<0.001$ \\
\hline & 2007-08 & 0.013 & 0.079 & 0.999 & $<0.001$ \\
\hline & 2008-11 & $<0.001$ & $<0.001$ & 0.999 & $<0.001$ \\
\hline & 2011-12 & $<0.001$ & 0.006 & 0.999 & $<0.001$ \\
\hline \multirow[t]{4}{*}{ Other } & $2006-07$ & 0.015 & 0.023 & 0.030 & 0.056 \\
\hline & 2007-08 & 0.015 & 0.027 & 0.015 & 0.030 \\
\hline & 2008-11 & $<0.001$ & $<0.001$ & 0.006 & 0.016 \\
\hline & 2011-12 & 0.001 & 0.003 & 0.012 & 0.025 \\
\hline \multirow[t]{4}{*}{ Boats (in developed) } & 2006-07 & 0.035 & 0.059 & 0.833 & 0.290 \\
\hline & 2007-08 & 0.036 & 0.058 & 0.702 & 0.452 \\
\hline & 2008-11 & $<0.001$ & $<0.001$ & 0.495 & 0.560 \\
\hline & 2011-12 & 0.002 & 0.009 & 0.661 & 0.529 \\
\hline \multirow[t]{4}{*}{ Boats (in deciduous) } & 2006-07 & 0.651 & 0.262 & 0.014 & 0.028 \\
\hline & $2007-08$ & 0.653 & 0.235 & 0.007 & 0.013 \\
\hline & 2008-11 & $<0.001$ & $<0.001$ & 0.003 & 0.006 \\
\hline & 2011-12 & 0.105 & 0.344 & 0.005 & 0.011 \\
\hline \multirow[t]{4}{*}{ People (in developed) } & 2006-07 & 0.031 & 0.052 & 0.036 & 0.052 \\
\hline & $2007-08$ & 0.031 & 0.048 & 0.018 & 0.027 \\
\hline & 2008-11 & $<0.001$ & $<0.001$ & 0.007 & 0.015 \\
\hline & 2011-12 & 0.002 & 0.008 & 0.015 & 0.027 \\
\hline \multirow[t]{2}{*}{ People (in deciduous) } & 2006-07 & 0.621 & 0.351 & $<0.001$ & $<0.001$ \\
\hline & $2007-08$ & 0.623 & 0.307 & $<0.001$ & $<0.001$ \\
\hline
\end{tabular}


2008-11

$<0.001$

$<0.001$

0.093

0.332

$<0.001$

$<0.001$

2011-12

0.332

$<0.001$

$<0.001$ 
Table 7. Summer estimates of the probabilities of bald eagle emigration and colonization in the Chesapeake Bay from 2006 to 2012 (standard errors (SE)) in oligohaline waters, within different land cover types between study years.

\begin{tabular}{|c|c|c|c|c|c|}
\hline \multirow[b]{2}{*}{ Variable } & \multirow[b]{2}{*}{ Year } & \multicolumn{2}{|c|}{ Emigration } & \multicolumn{2}{|c|}{ Colonization } \\
\hline & & Probability & $\mathrm{SE}$ & Probability & $\mathrm{SE}$ \\
\hline \multirow[t]{4}{*}{ Developed } & $2006-07$ & $<0.001$ & $<0.001$ & $<0.001$ & 0.001 \\
\hline & $2007-08$ & $<0.001$ & $<0.001$ & $<0.001$ & $<0.001$ \\
\hline & $2008-11$ & $<0.001$ & $<0.001$ & $<0.001$ & $<0.001$ \\
\hline & 2011-12 & $<0.001$ & $<0.001$ & $<0.001$ & $<0.001$ \\
\hline \multirow[t]{4}{*}{ Wetlands } & 2006-07 & $<0.001$ & $<0.001$ & $<0.001$ & $<0.001$ \\
\hline & 2007-08 & $<0.001$ & $<0.001$ & $<0.001$ & $<0.001$ \\
\hline & 2008-11 & $<0.001$ & $<0.001$ & $<0.001$ & $<0.001$ \\
\hline & 2011-12 & $<0.001$ & $<0.001$ & $<0.001$ & $<0.001$ \\
\hline \multirow[t]{4}{*}{ Deciduous } & 2006-07 & $<0.001$ & $<0.001$ & $<0.001$ & $<0.001$ \\
\hline & $2007-08$ & $<0.001$ & $<0.001$ & $<0.001$ & $<0.001$ \\
\hline & $2008-11$ & $<0.001$ & $<0.001$ & $<0.001$ & $<0.001$ \\
\hline & 2011-12 & $<0.001$ & $<0.001$ & $<0.001$ & $<0.001$ \\
\hline \multirow[t]{4}{*}{ Evergreen } & 2006-07 & $<0.001$ & 0.004 & 1.0000 & $<0.001$ \\
\hline & 2007-08 & $<0.001$ & 0.004 & 1.0000 & $<0.001$ \\
\hline & 2008-11 & $<0.001$ & $<0.001$ & 1.0000 & $<0.001$ \\
\hline & 2011-12 & $<0.001$ & $<0.001$ & 1.0000 & $<0.001$ \\
\hline \multirow[t]{4}{*}{ Mixed Forest } & 2006-07 & $<0.001$ & $<0.001$ & 0.997 & 0.030 \\
\hline & 2007-08 & $<0.001$ & $<0.001$ & 0.993 & 0.064 \\
\hline & $2008-11$ & $<0.001$ & $<0.001$ & 0.982 & 0.155 \\
\hline & 2011-12 & $<0.001$ & $<0.001$ & 0.991 & 0.079 \\
\hline \multirow[t]{4}{*}{ Other } & 2006-07 & $<0.001$ & $<0.001$ & $<0.001$ & $<0.001$ \\
\hline & 2007-08 & $<0.001$ & $<0.001$ & $<0.001$ & $<0.001$ \\
\hline & $2008-11$ & $<0.001$ & $<0.001$ & $<0.001$ & $<0.001$ \\
\hline & 2011-12 & $<0.001$ & $<0.001$ & $<0.001$ & $<0.001$ \\
\hline \multirow[t]{4}{*}{ Boats (in developed) } & $2006-07$ & $<0.001$ & $<0.001$ & 0.008 & 0.021 \\
\hline & $2007-08$ & $<0.001$ & $<0.001$ & 0.004 & 0.011 \\
\hline & $2008-11$ & $<0.001$ & $<0.001$ & 0.002 & 0.005 \\
\hline & $2011-12$ & $<0.001$ & $<0.001$ & 0.003 & 0.010 \\
\hline \multirow[t]{4}{*}{ Boats (in deciduous) } & $2006-07$ & $<0.001$ & $<0.001$ & $<0.001$ & $<0.001$ \\
\hline & 2007-08 & $<0.001$ & $<0.001$ & $<0.001$ & $<0.001$ \\
\hline & $2008-11$ & $<0.001$ & $<0.001$ & $<0.001$ & $<0.001$ \\
\hline & 2011-12 & $<0.001$ & $<0.001$ & $<0.001$ & $<0.001$ \\
\hline \multirow[t]{4}{*}{ People (in developed) } & $2006-07$ & $<0.001$ & $<0.001$ & $<0.001$ & $<0.001$ \\
\hline & $2007-08$ & $<0.001$ & $<0.001$ & $<0.001$ & $<0.001$ \\
\hline & $2008-11$ & $<0.001$ & $<0.001$ & $<0.001$ & $<0.001$ \\
\hline & $2011-12$ & $<0.001$ & $<0.001$ & $<0.001$ & $<0.001$ \\
\hline \multirow[t]{2}{*}{ People (in deciduous) } & 2006-07 & $<0.001$ & $<0.001$ & $<0.001$ & $<0.001$ \\
\hline & $2007-08$ & $<0.001$ & $<0.001$ & $<0.001$ & $<0.001$ \\
\hline
\end{tabular}


2008-11

$<0.001$

$<0.001$

$<0.001$

$<0.001$

2011-12

$<0.001$

$<0.001$

$<0.001$

$<0.001$ 
Table 8. Summer estimates of the probabilities of bald eagle emigration and colonization in the Chesapeake Bay from 2006 to 2012 (standard errors (SE)) in mesohaline waters, within different land cover types between study years.

\begin{tabular}{|c|c|c|c|c|c|}
\hline \multirow[b]{2}{*}{ Variable } & \multirow[b]{2}{*}{ Year } & \multicolumn{2}{|c|}{ Emigration } & \multicolumn{2}{|c|}{ Colonization } \\
\hline & & Probability & $\mathrm{SE}$ & Probability & $\mathrm{SE}$ \\
\hline \multirow[t]{4}{*}{ Developed } & $2006-07$ & 0.070 & 0.130 & $<0.001$ & $<0.001$ \\
\hline & 2007-08 & 0.071 & 0.116 & $<0.001$ & $<0.001$ \\
\hline & $2008-11$ & $<0.001$ & $<0.001$ & $<0.001$ & $<0.001$ \\
\hline & 2011-12 & 0.005 & 0.020 & $<0.001$ & $<0.001$ \\
\hline \multirow[t]{4}{*}{ Wetlands } & 2006-07 & 0.095 & 0.123 & $<0.001$ & $<0.001$ \\
\hline & 2007-08 & 0.096 & 0.128 & $<0.001$ & $<0.001$ \\
\hline & $2008-11$ & $<0.001$ & $<0.001$ & $<0.001$ & $<0.001$ \\
\hline & 2011-12 & 0.007 & 0.025 & $<0.001$ & $<0.001$ \\
\hline \multirow[t]{4}{*}{ Deciduous } & 2006-07 & 0.793 & 0.312 & $<0.001$ & $<0.001$ \\
\hline & 2007-08 & 0.795 & 0.270 & $<0.001$ & $<0.001$ \\
\hline & 2008-11 & $<0.001$ & $<0.001$ & $<0.001$ & $<0.001$ \\
\hline & 2011-12 & 0.194 & 0.656 & $<0.001$ & $<0.001$ \\
\hline \multirow[t]{4}{*}{ Evergreen } & 2006-07 & 0.979 & 0.086 & 1.0000 & $<0.001$ \\
\hline & 2007-08 & 0.979 & 0.087 & 1.0000 & $<0.001$ \\
\hline & $2008-11$ & $<0.001$ & 0.001 & 1.0000 & $<0.001$ \\
\hline & 2011-12 & 0.745 & 1.023 & 1.0000 & $<0.001$ \\
\hline \multirow[t]{4}{*}{ Mixed Forest } & 2006-07 & 0.017 & 0.104 & $<0.001$ & $<0.001$ \\
\hline & 2007-08 & 0.017 & 0.102 & $<0.001$ & $<0.001$ \\
\hline & 2008-11 & $<0.001$ & $<0.001$ & $<0.001$ & $<0.001$ \\
\hline & 2011-12 & 0.001 & 0.008 & $<0.001$ & $<0.001$ \\
\hline \multirow[t]{4}{*}{ Other } & 2006-07 & 0.020 & 0.030 & $<0.001$ & $<0.001$ \\
\hline & 2007-08 & 0.020 & 0.035 & $<0.001$ & $<0.001$ \\
\hline & $2008-11$ & $<0.001$ & $<0.001$ & $<0.001$ & $<0.001$ \\
\hline & 2011-12 & 0.001 & 0.004 & $<0.001$ & $<0.001$ \\
\hline \multirow[t]{4}{*}{ Boats (in developed) } & 2006-07 & 0.046 & 0.078 & $<0.001$ & $<0.001$ \\
\hline & $2007-08$ & 0.046 & 0.075 & $<0.001$ & $<0.001$ \\
\hline & $2008-11$ & $<0.001$ & $<0.001$ & $<0.001$ & $<0.001$ \\
\hline & 2011-12 & 0.003 & 0.012 & $<0.001$ & $<0.001$ \\
\hline \multirow[t]{4}{*}{ Boats (in deciduous) } & 2006-07 & 0.710 & 0.286 & $<0.001$ & $<0.001$ \\
\hline & 2007-08 & 0.712 & 0.262 & $<0.001$ & $<0.001$ \\
\hline & $2008-11$ & $<0.001$ & $<0.001$ & $<0.001$ & $<0.001$ \\
\hline & 2011-12 & 0.133 & 0.423 & $<0.001$ & $<0.001$ \\
\hline \multirow[t]{4}{*}{ People (in developed) } & $2006-07$ & 0.041 & 0.069 & $<0.001$ & $<0.001$ \\
\hline & 2007-08 & 0.041 & 0.063 & $<0.001$ & $<0.001$ \\
\hline & $2008-11$ & $<0.001$ & $<0.001$ & $<0.001$ & $<0.001$ \\
\hline & 2011-12 & 0.003 & 0.011 & $<0.001$ & $<0.001$ \\
\hline \multirow[t]{2}{*}{ People (in deciduous) } & $2006-07$ & 0.683 & 0.361 & $<0.001$ & $<0.001$ \\
\hline & 2007-08 & 0.685 & 0.321 & $<0.001$ & $<0.001$ \\
\hline
\end{tabular}


2008-11 <0.001

$<0.001$

$<0.001$

$<0.001$

2011-12

0.119

0.412

$<0.001$

$<0.001$ 
Table 9. Estimates of bald eagle probabilities and their associated standard errors (SE) for each model parameter (occupancy, movement, colonization) by age and salinity class. These results show the probabilities of different aged bald eagles occupying certain salinities in the Chesapeake Bay in the winter seasons (2006 to 2012).

\begin{tabular}{cccccccc}
\hline & & \multicolumn{2}{c}{ Occupancy } & \multicolumn{2}{c}{ Emigration } & \multicolumn{2}{c}{ Colonization } \\
\cline { 3 - 7 } Salinity & Age & Probability & SE & Probability & SE & Probability & SE \\
\hline Tidal Fresh & Hatch Year & 0.396 & 0.105 & 0.295 & 0.153 & 0.728 & 0.131 \\
& Subadult & 0.492 & 0.076 & 0.286 & 0.125 & 0.523 & 0.139 \\
& Adult & 0.431 & 0.045 & 0.150 & 0.045 & 0.174 & 0.042 \\
Oligohaline & Hatch Year & 0.486 & 0.108 & 0.260 & 0.144 & 0.358 & 0.173 \\
& Subadult & 0.523 & 0.074 & 0.252 & 0.120 & 0.186 & 0.116 \\
& Adult & 0.523 & 0.045 & 0.129 & 0.049 & 0.042 & 0.026 \\
Mesohaline & Hatch Year & 0.235 & 0.125 & 0.027 & 0.000 & 0.438 & 0.232 \\
& Subadult & 0.312 & 0.111 & 0.026 & 0.000 & 0.242 & 0.145 \\
& Adult & 0.263 & 0.093 & 0.012 & 0.000 & 0.058 & 0.066 \\
\hline
\end{tabular}




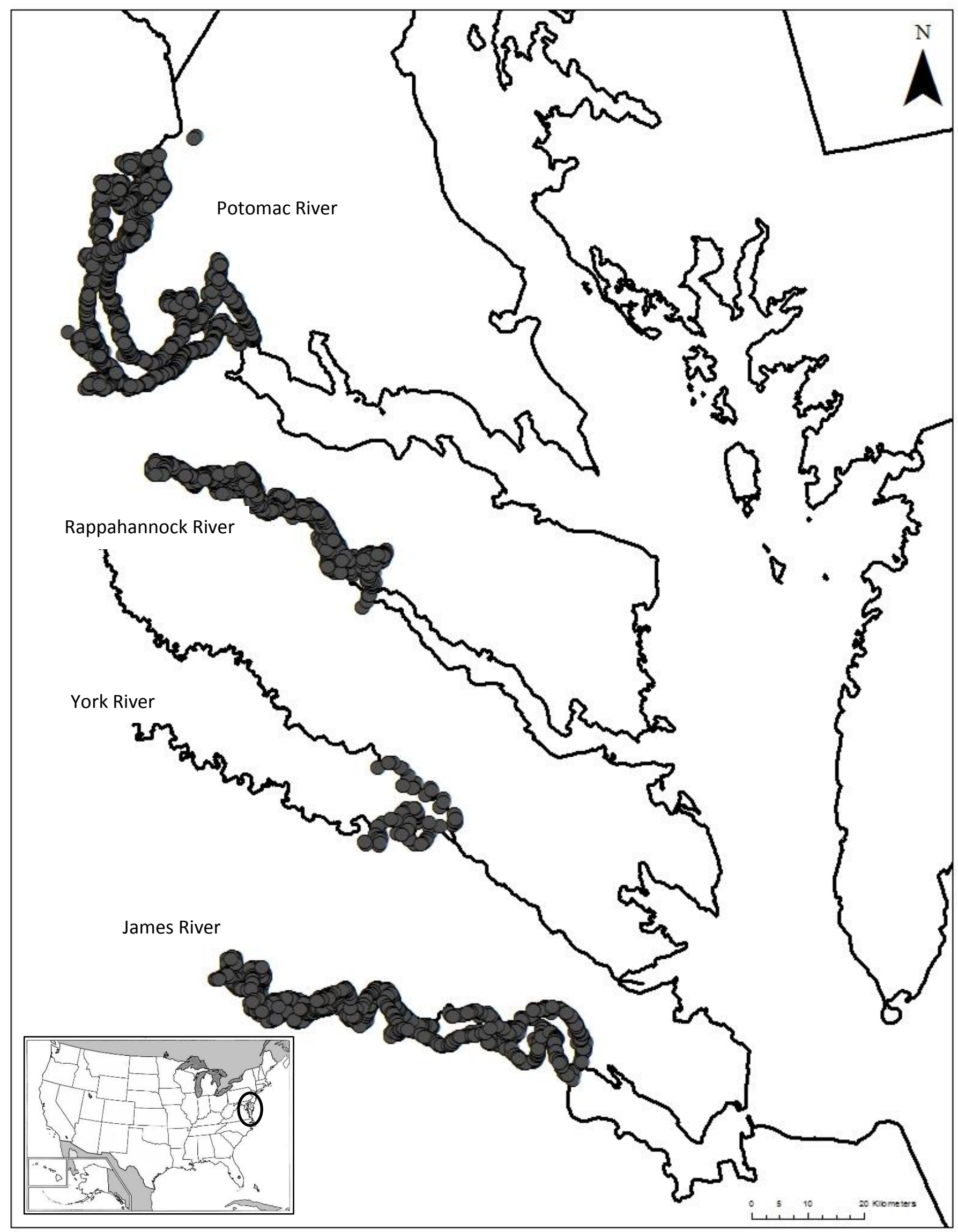




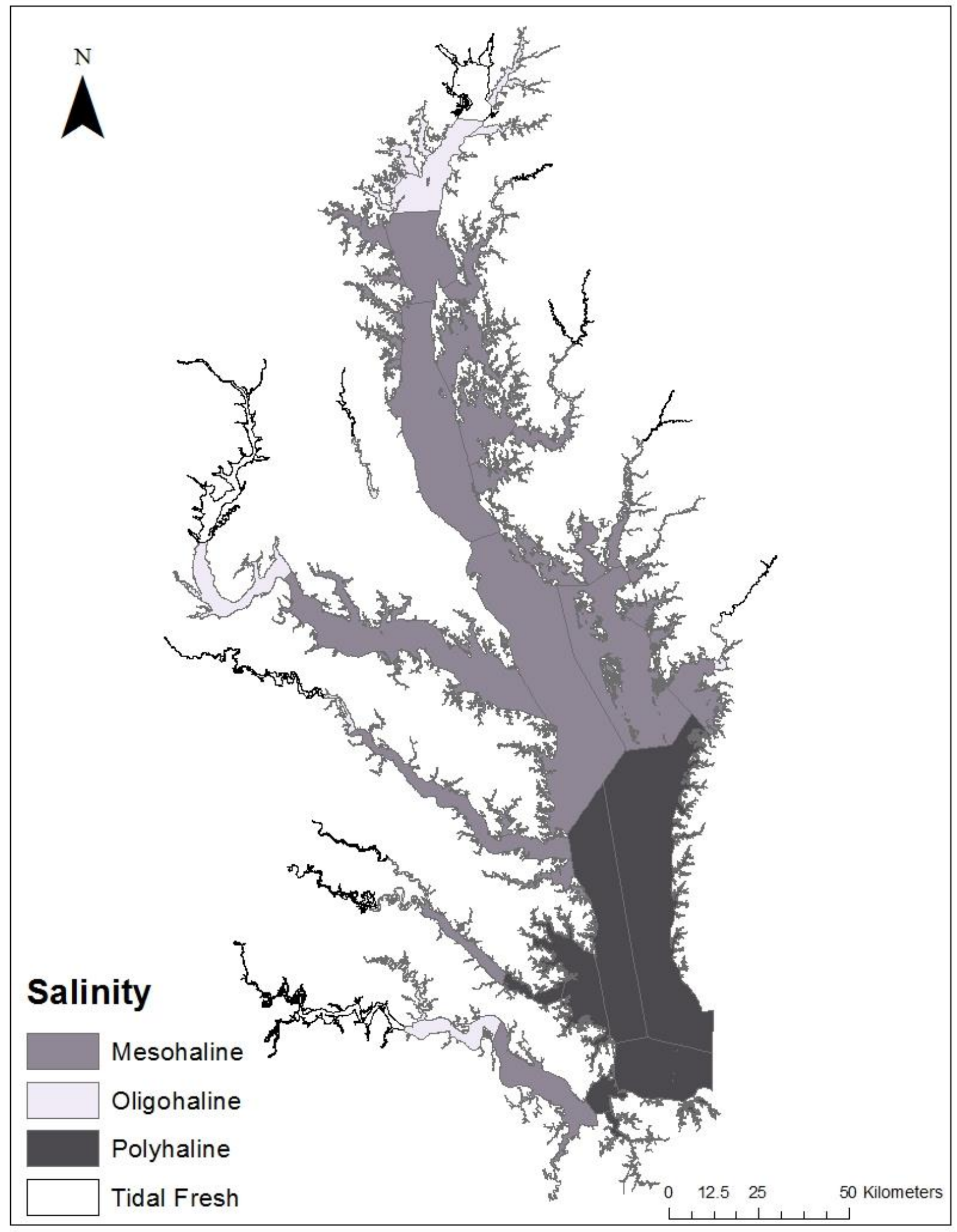


20 April 2018

Bethany Drahota

West Virginia University

$1472556^{\text {th }}$ Ave W

Edmonds, WA 98026

206-512-7852 (phone)

bdrahota@gmx.com

Drahota et al. • Density of Bald Eagles

Determining Bald Eagle Density Using Occupancy Models

BETHANY M. DRAHOTA ${ }^{1}$, Division of Forestry and Natural Resources, West Virginia

University, PO Box 6125, Morgantown, WV 26506 USA

ADAM DUERR ${ }^{2}$, Division of Forestry and Natural Resources, West Virginia University, PO

Box 6125, Morgantown, WV 26506 USA

JEFF L. COOPER, Virginia Department of Game and Inland Fisheries, 1320 Belman Road,

Fredericksburg, VA 22401, USA

JAMES T. ANDERSON, Division of Forestry and Natural Resources, West Virginia University,

PO Box 6125, Morgantown, WV 26506 USA

SERGIO HARDING, Virginia Department of Game and Inland Fisheries, 1320 Belman Road, Fredericksburg, VA 22401, USA

TODD E. KATZNER, U.S. Geological Survey, Forest \& Rangeland Ecosystem Science Center, 970 Lusk Street, Boise, ID, 83706, USA

${ }^{1}$ Email: bdrahota@gmx.com

${ }^{2}$ Current address: Bloom Research, Inc. 1358 1/2 S Cloverdale Avenue, Los Angeles, CA USA 90019

ABSTRACT Bald eagles (Haliaeetus leucocephalus) are a species of concern with a unique conservation history that has led to intense monitoring over many years. Managers are 
increasingly looking to evaluate population numbers and growth in focal areas of importance, such as the Chesapeake Bay on the East coast of the United States. Our study used seven years of mark-resight data from the Chesapeake Bay to determine the density of bald eagles in the region and their associations with land cover and salinity. We used Royle-Poisson occupancy models to find average abundance and multiply this across the number of units in our study area to determine effective density. Models suggested that canopy cover type may be important. However, the models we used appeared inappropriate for the data and therefore, they did not converge, and our results were generally uninformative. We suggest that future monitoring in the region be done with specific models and objectives in mind and use a single sampling strategy. Archived data from mandated monitoring of sensitive species are valuable to the scientific community; however, if the models used are not appropriate for the data collected, the ability to answer specific research questions becomes limited.

KEY WORDS bald eagle, Chesapeake Bay, density, mark-resight, Poisson, presence-absence. Estimating abundance and density is essential in the study of wildlife ecology (Krebs 2001, Chandler and Royle 2013, Ivan et al. 2013, Dennis et al. 2015). In practice, density (number of animals per unit of area; Anderson et al. 1983) is often easier to interpret than is abundance (number of animals of a species present; Kéry et al. 2005). However, given the mobile nature of wildlife, density estimates can be more difficult to obtain because they require a clearly defined geographic extent (Anderson et al. 1983, Chandler and Royle 2013). Nevertheless, both density and abundance are valuable metrics as they can capture population variations over time.

In mark-resight studies where individuals are often unmarked, as opposed to markrecapture studies, n-mixture models (Royle 2004) are often employed to obtain more accurate 
density estimates (MacKenzie et al. 2009, Chandler and Royle 2013). These models are used with datasets that were collected at a set number of $k$ sites with $t$ replications at each site (Chandler and Royle 2013). These methods can then be used to obtain abundance estimates for individual sites, for average abundances across sites, and for density across a geographic range. N-mixture models can also be used to estimate the effect of external factors, such as land cover, on population estimates (Royle 2004, Chandler and Royle 2013). Finally, these models also allow for more cost-effective sampling designs than traditional methods that rely on animal capture and marking (i.e., mark-recapture, multiple observer, etc.; Royle 2004, Dennis et al. 2015). N-mixture models are especially useful for species with extensive monitoring histories, where archived data are readily available.

The unique conservation and management history of bald eagles (Haliaeetus leucocephalus) has caused them to be heavily monitored. In the past, eagle populations were negatively impacted by persecution, poisoning, and habitat deterioration and, subsequently, enhanced by management action (Seasholes 2013). Listed at different times as an endangered and then a threatened species, and then removed from the Endangered Species List in 2007, the bald eagle is still considered a species of concern throughout North America. As such, density and abundance of bald eagles is of conservation importance. The goal of this study was to use nmixture models to estimate the abundance and density of bald eagles in three tributaries of the Chesapeake Bay in Virginia, USA.

Our specific study objectives were to: (i) use n-mixture models to estimate density of bald eagles along the James, Rappahannock, Potomac, and York Rivers in summer; (ii) use those same models to evaluate how landscape features (salinity and land cover type) influenced that 
density; and (iii) understand how n-mixture models may be useful in the context of archived data.

\section{STUDY AREA}

The Chesapeake Bay watershed extends from New York to the Carolinas (Buehler et al. 1991). with tributaries spanning greater than $250-\mathrm{km}$. Data for this study were collected from along four major rivers in the Southern Chesapeake Bay: Rappahannock, Potomac, James, and York. Landcover along these rivers included forested land, wetlands, and developed areas, both industrial and residential (Thompson et al. 2005). Salinity within the Bay varies, ranging from polyhaline (30-18 ppt, near river mouths) to tidal fresh (<0.5ppt, inland areas) (VIMS 2004). The vegetation along the shoreline primarily consists of deciduous forest cover. Within the water, submerged aquatic vegetation is abundant. Taxa within the Bay include a variety of fish and bird populations, small mammals, amphibians, and raptors, including bald eagles (Brown and Erdle 2009).

\section{METHODS}

\section{Data Collection}

Data were collected via repeated transect surveys during summer (June, July, August) and winter seasons (December, January, February) 2006-2012. Sampling occurred 1 to 2 times per month on each river and year. Surveys were done by both boat and fixed-wing aircraft by the Virginia Department of Game and Inland Fish (VDGIF) and by the Center for Conservation Biology (CCB) at the College of William and Mary (Table 1).

Boat surveys had a minimum two-person field crew per survey. Observers monitored one side of the shoreline on the outbound trip and monitored the opposite side on their return. Boats moved approximately 15-20 kph (weather dependent) about 200-m offshore. Aircraft surveys 
were conducted from a 172 High-wing Cessna (Crabbe Aviation, Hanover, MA) with one eagle spotter, one mapper (who also assisted with spotting), and the pilot. For both survey types, the crew noted eagle observations on regional 1:24,000 topographical maps and coordinates were recorded into a hand-held Geographic Positioning System (Garmin 76 GPSmap 2016). Observers on boat surveys classified birds into one of seven classes: hatch year, second year, third year, fourth year, adult, juvenile (subadult of unknown age), or unknown. Observers on aircraft surveys placed bald eagles into one of two classes: adult or juvenile (any bird younger than adult).

\section{Data Classification}

We used the Geospatial Modeling Environment (v. 0.7.3.0 (Beyer 2012)) within ArcMap 10.2 (ESRI 2011) to divide each river into individual units. Each unit was 1-km length-wise by 6-km width-wise. The units originated from each river mouth and continued over the entire portion of the river covered by our surveys (Figure 1). Data collected were linked to both salinity estimates (VIMS 2004) and to the 2006 National Land Cover Database (NLCD; Fry et al. 2011).

We condensed land use and cover into five separate categories: developed, wetlands, cultivated areas, open, and canopy cover (deciduous, evergreen, and mixed cover). We calculated and assigned percent land cover to each river unit using ArcMap. Further, survey data were linked to one of four classes (tidal fresh $(<0.5 \mathrm{ppt})$, oligohaline $(0.5-5.0 \mathrm{ppt})$, mesohaline (>5.0-18 ppt), and polyhaline (>18.0-30.0 ppt)) using published salinity data (Figure 2; VIMS 2004).

We used the point distance tool in ArcMap to link each eagle observation to a river unit and imported these data into Microsoft Excel (Redmond, WA). We used pivot tables to create a single line of eagle presence or absence records for each age class on each river unit. 


\section{Data Analysis}

The two lines of eagle presence or absence records formed the capture histories that we imported into Program MARK for subsequent analysis. To estimate the density of bald eagles (objective $i$ ), we used a Royle-Poisson count model (n-mixture model; Royle 2004) within Program MARK (White and Burnham 1999). This model type estimates mean population sizes and individual detection probabilities (modeled estimates), as well as occupancy and average detection probabilities (derived estimates). Density can then be calculated from site-specific population estimates. To evaluate how landscape features influenced that density (objective ii), we ran a sub-set of 7 models that included combinations of land cover types and their effects on the modeled and derived estimates (see Table 2). These models were set up to look in-depth at the effects of both individual characteristics (i.e., wetlands, salinity) and the effect of multiple characteristics combined (i.e., terrestrial land cover vs. land cover with salinity, Table 2). These analyses allowed us to understand how archived data may be useful in the context of n-mixture models (objective $i i i)$.

\section{RESULTS}

\section{Summary Statistics}

The dataset we modeled included 810 river units in summer with 29 total surveys. We observed 29,719 bald eagles with an average of 37 eagles/unit $(\mathrm{SE}=2.26)$ and 1,023 eagles/survey ( $\mathrm{SE}=11.763)$. Of the units sampled, 252 units were in tidal fresh waters, 247 were in oligohaline, 296 were in mesohaline, and 15 were in polyhaline waters. In tidal fresh water there were an average of 538 eagles/survey ( $\mathrm{SE}=13.528)$, compared to 364 eagles/survey $(\mathrm{SE}=12.353)$ in oligohaline waters, 123 eagles/survey $(\mathrm{SE}=7.290)$ in mesohaline, and 30 eagles/survey $(\mathrm{SE}=16.516)$ in polyhaline waters (Table 3). 
We evaluated eagle observations within land cover class by considering the number of eagles present where a land cover type held greater than $30 \%$ of the river unit. Because there was some overlap in land cover among units, a given unit could be represented in more than one cover type. In summer, the raw data we recorded averaged higher numbers of eagles in croplands, wetlands, deciduous tree cover, and open lands. Overall canopy cover (all three forest classes) also had relatively high numbers of eagles present. There were lower numbers of eagles recorded in evergreen tree cover, developed lands, and mixed forests (Table 3). Winter bald eagle observations had the highest number of eagles recorded in croplands, deciduous cover, canopy cover (all three forest types), and open lands. Somewhat fewer eagles were in evergreen cover and developed lands, and much fewer eagles were seen in mixed forest cover (Table 3).

\section{Bald Eagle Density}

For this analysis, we only considered data collected during the summer season (810 units). Even with the use of n-mixture models, model results were generally poor and somewhat uninformative. The model with the best support in the data was the null or intercept model (AICc: 0.00; model weight: 0.71) (Table 2). In this model, estimates of mean population size and individual detection probability were generated, but the estimates were zero across all age classes (Table 4). Additionally, real estimates had standard errors of zero (Table 4). Further, derived estimates of average detection probabilities could not be calculated within Program MARK, and derived occupancies were uninformative, making calculations of bald eagle densities impossible (Table 4).

The summer model with the most support in the data was the null model that did not include any environmental effects. From this model, the probability of either an adult bald eagle or a juvenile bald eagle being individually detected were 0.00 , an indication that results are not 
meaningful. The average population size for adult eagles was $1.65 \times 10^{31}$ and $1.50 \times 10^{33}$ for juveniles (Table 4). With these values, the density of adult bald eagles in the survey area (810 river units) was $1.34 \times 10^{34}$ and juvenile density in the survey area was $1.22 \times 10^{36}$ (objective $i$ ). Considering the total number of eagles observed in summer was 29,719 , the model estimate of bald eagles' density is extremely high and is another indicator that the model did not perform well and was not estimating population size effectively. The effect of landscape features on the density (objective ii) was limited, and bald eagles did not appear to select spaces based on any outside factors. Estimates of occupancy were 1.00 within our study area and because of this $100 \%$ occupancy rate combined with high abundances, average detection probabilities could not be calculated and not all outputs were given a numerical value (Table 4).

The second-best model within the set, canopy cover (AICc: 4.00; model weight: 0.0196), suggested that the probability of detecting an adult bald eagle within canopy cover (deciduous, evergreen, or mixed) was 0.00 and juveniles was 0.00 also. Real estimates from this model likewise rounded to show a probability of detection of 0.00 .

\section{DISCUSSION}

Data collected for legally mandated wildlife monitoring purposes are collected to meet those specific monitoring objectives. Therefore, those data may or may not be well suited to incorporation into demographic modeling. Although occupancy analyses tend to work well with data that were not collected with a priori hypotheses, we were unable to obtain informative estimates of population size with the data we considered. Given the ineffectiveness of n-mixture models to produce reasonable estimates in this situation, we believe the data were insufficient for these models to converge properly. As such, it was difficult to use these models to understand density and habitat use by eagles (objectives $i$ and $i i$ ), and we focus our discussion only on 
interpreting naïve estimates of density and on the applicability of these archived data for use in n-mixture models (objective iii).

\section{Archived Data for Modeling}

The count-based occupancy models used in this study do not require marking individuals and are thought to work well with sampling designed for other objectives (i.e., data collected at uneven intervals or missing data). However, there were some inconsistencies in sampling that made it challenging for us to use n-mixture models with these data. Here we discuss some of the challenges we faced with utilizing n-mixture models to reach our objectives.

Because the data set we considered was so large scale and long term, multiple sampling teams collected data, and each used slightly different approaches to field work. Furthermore, there was inconsistency in sampling vessel types (i.e., aircraft versus boat). Observers on boat surveys classified bald eagles into seven different age classes (i.e., hatch year, second year, third year, fourth year, adult, juvenile, and unknown) and collected information on recreational activities (boats and people). However, observers did not range far into the center of the bay and so some land cover and salinity areas were sampled unevenly (i.e., they primarily sampled low salinity areas). Observers on aerial surveys classified bald eagles into one of two age classes (juvenile and adult) and did not note any recreational presence. However, they did collect eagle observations over a broader geographic range, catching more variation in land cover and salinity type. To have sufficient sample sizes to model occupancy, and density by extension, we needed to merge the two survey types, which resulted in a loss of detail. We were unable to include individual age classes or recreation in our density analysis, and the study area was heavily skewed to more inland areas. All these factors likely influenced the utility of the data set for the modeling approach we used. 
Another limiting factor was the irregularity of survey periods. Long-term mandated surveys often end up being conducted whenever there are time and people available. Likewise, variation in seasonal weather conditions influenced survey effort, especially in winter when rivers froze over and surveying windows were small. Although this was reasonable given the goals of the data collection, these irregularities made it challenging for us to scientifically interpret these data. Surveys were not always done in the same months each year and some years had no surveys at all. These irregularities created holes in our input file, making proper numerical convergence hard to obtain, even with so many data.

With many models that estimate abundance, collected data must be subject to geographic and population closure over the course of the study (Dennis et al. 2015). This was unlikely in our study as it is unreasonable to assume geographic and population closure over such a large area and multiple years of surveys with a migratory species. Additionally, accounting for imperfect detection is fraught with challenges in most models (MacKenzie et al. 2009), and our study was no exception. While the ability to obtain abundance estimates without marking individuals is an appealing option, this is extremely difficult and mostly unreasonable to achieve (Barker et al. 2017).

While our results were limited and none of the effect sizes differed, we did see a general pattern that results tended to be stronger without any of the environmental variables that we tested (canopy cover, wetlands, open, development, and cultivated lands). This could mean that bald eagles are not nearly as selective in choosing landscape spaces as was previously thought (Buehler et al. 1991). Additionally, looking at other models from our dataset, three models were tied for second (AICc: 4.00; weight: 0.096). These were canopy cover, anthropogenic (development), and wetlands. Although these models were not the most supported, they do 
provide insight into what environmental factors, if any, might influence bald eagles. These results were surprising, given the extensive research showing the importance of salinity and land cover type for eagle habitat (Buehler et al. 1991, Watts et al. 2006, Watts et al. 2007). However, given that none of the models provided accurate estimates, it is likely that the data were not fitted well and drawing conclusions from these models may be inappropriate. Future research should look at this further and see if these results hold up with a more appropriate dataset.

\section{Naïve Estimates}

Occupancy models provide us with valuable information on the influence of detection probability on population size. Knowing detection rates is essential to the comprehensive understanding of patterns in demographic changes. However, in the absence of detection rates, naïve estimates of demographic rates may be somewhat informative, if interpreted with caution, and provided that resight probability did not have a greater effect on the naïve estimates than the actual population size (i.e., if population size remained constant between sampling occasions, then resight probability may have been responsible for the different counts observed). Given the challenges we faced in obtaining estimates from occupancy modeling, we found it worthwhile to look at the naïve estimates of bald eagles in our study area. In this setting, the bald eagles we monitored showed trends in environmental preferences that provide some limited insight into the relative importance of different habitat types to eagles.

Naïve estimates derived from survey data suggested that river units containing tidal fresh waters held greater numbers of eagles than any of the other habitat types we considered. Considering this, naïve estimates of bald eagles' presence suggest that lower saline waters are used with more frequency, a pattern that is comparable to those previously reported and potentially linked to distribution of prey populations (Buehler et al. 1991, Watts et al. 2006, 
Watts et al. 2007). It is noteworthy that several previous studies looking at salinity use by bald eagles drew conclusions from naïve estimates (Watts et al. 2006, Watts et al. 2007), some of which may have been based on the same data we use in this analysis.

Of the land cover characteristics we considered, cultivated croplands had the highest average number of bald eagles per unit, followed by wetlands. Both mixed forests and developed areas had very low numbers of eagles, while open areas, deciduous forests, and overall canopy cover were comparable and relatively high. High numbers of eagles in cultivated croplands was a surprising find and may suggest higher tolerance by bald eagles to landscape changes. Given the openness of these areas, it's possible eagles are using croplands for perching and observing prey. Alternatively, this may simply be a result of higher visibility in open areas and thus, higher detection of bald eagles. Wetland areas were likely used by higher numbers of eagles because of their foraging potential, as these areas are often nearer to open water and house many different fish and waterbird populations. Further, finding high numbers of bald eagles in river units with canopy cover was unsurprising because trees are commonly used for both perching and nesting.

The results of our modeling suggested that the covariates with the strongest influence on bald eagle distribution were canopy cover, wetlands, and development. Considering these results, we would have expected the naïve estimates to show that these three cover types were likewise inhabited by higher numbers of eagles. However, developed lands held very few eagles compared to canopy cover and wetlands. In fact, the three cover types with the highest naïve estimates of eagle density were croplands, wetlands, and deciduous forests. This disparity is likely caused by the models' ability to incorporate the probability of detecting an eagle into estimates and gives insight as to the value of our occupancy models, even with poorer results. 


\section{Next Steps}

We could improve model estimates by altering sampling and modeling strategies. Consistency in data collection and gearing sampling towards a specific modelling approach would be the most important changes. This includes consistency in sampling periods (i.e., having a predetermined number of surveys; minimizing missing data will strengthen these data for later modeling); sampling methods (i.e., consistent transportation type; boat vs. plane); and consistency in bald eagle age classifications. To this end, if managers are looking to obtain information on bald eagle age distributions, boat surveys are the ideal option as observers can classify eagle ages more accurately at close range. On the other side, if information on overall bald eagle distributions are the research goal, then aerial surveys would be a better option as these survey types are better able to observe larger numbers of eagles in shorter time periods. Additionally, to obtain informative estimates, we needed to meet expectations of geographic and demographic closure, which can be a challenge in broad-scale study areas. Sampling within smaller time windows (1-2 months post migration in either season) could help with demographic closure because observations would be limited to set populations rather than during migration periods when populations are in flux. Given that data were collected in a set study area, geographic closure was well accounted for; however, this could be made simpler by focusing on fewer rivers or otherwise limiting the area.

Model estimates may also be improved by selecting a study design prior to sampling and setting a priori hypotheses or objectives. For example, rather than trying to obtain abundance and density estimates, we could look at basic occupancy, movement, or changes in age structure. Occupancy models, such as the n-mixture model that we employed, are one of the only model types able to fit data without individually marked animals (Barker et al. 2017). However, if these 
models cannot be used to meet study objectives, it may be necessary to switch to a model that is appropriate for the data. One potential solution could be to use methods that estimate resight

probability in order to correct population counts. If those counts are linked to a known study area, they could be used to estimate density (Duerr et al. 2015).

\section{MANAGEMENT IMPLICATIONS}

Archived data can be ecologically valuable and provide insight into species demographics. These data can be useful for making future management decisions, as sensitive species require continual monitoring, and may have a plethora of data available. Through occupancy modeling, these data can be utilized effectively if they are collected consistently and with clear modeling objectives prior to sampling.

\section{ACKNOWLEDGMENTS}

We thank the many organizations who contributed and supported this project including: The Virginia Department of Game and Inland Fisheries and The College of William and Mary. J. A. was supported by the National Science Foundation under Cooperative Agreement OIA1458952 and by the USDA National Institute of Food and Agriculture, McIntire Stennis project WVA00117 during manuscript preparation. Any use of trade, product, or firm names is for descriptive purposes only and does not imply endorsement by the U.S. Government. This is Scientific Article number XXXX of the West Virginia University Agricultural and Forestry Experiment Station, Morgantown. 


\section{LITERATURE CITED}

Anderson, D. R., K. P. Burnham, G. C. White, and D. L. Otis. 1983. Density estimation of smallmammal populations using a trapping web and distance sampling methods. Ecology 64:674-690.

Barker, J. B., M. R. Schofield, W. A. Link, and J. R. Sauer. 2017. On the reliability of n-mixture models for count data. Biometrics 74:369-377.

Beyer, H. L. 2012. Geospatial modelling environment (Version 0.7.3.0). (Software). <http://www.spatialecology.com/gme>. Accessed 15 January 2014.

Brown, J., and S. Erdle. 2009. Amphibians, reptiles, birds, and mammals of the York River. Journal of Coastal Research SI(37):111-117.

Buehler, D. A., T. J. Mersmann, and J. D. Fraser. 1991. Differences in distribution of breeding, nonbreeding, and migrant bald eagles on the northern Chesapeake Bay. The Condor 93:399-408.

Chandler, R. B., and J. A. Royle. 2013. Spatially explicit models for inference about density in unmarked or partially marked populations. The Annals of Applied Statistics 7:936-954.

Dennis, E. B., B. J. T. Morgan, and M. S. Ridout. 2015. Computational aspects of n-mixture models. Biometrics 71:237-246.

Duerr, A. E., T. A. Miller, K. L. Cornell Duerr, M. J. Lanzone, A. Fesnock, and T. E. Katzner. 2015. Landscape-scale distribution and density of raptor populations wintering in anthropogenic-dominated desert landscapes. Biodiversity Conservation 24:2365-2381.

ESRI 2011. ArcGIS Desktop. Environmental Systems Research Institute, Release 10. Redlands, CA. 
Fry, J., G. Xian, S. Jin, J. Dewitz, C. Homer, L. Yang, C. Barnes, N. Herold, and J. Whickham. 2011. Completion of the 2006 National Land Cover Database for the conterminous United States. PE\&RS 77:858-864.

Ivan, J. S., G. C. White, and T. M. Shenk. 2013. Using simulation to compare methods for estimating capture-recapture data. Ecology 94:817-826.

Kéry, M., J. A. Royle, and H. Schmid. 2005. Modeling avian abundance from replicated counts using binomial mixture models. Ecological Applications 15:1450-1461.

Krebs, C. J. 2001. Ecology: the experimental analysis of distribution and abundance. Addison Wesley, Boston, MA.

MacKenzie, D. I., J. D. Nichols, M. E. Seamans, and R. J. Gutiérrez. 2009. Modeling species occurrence dynamics with multiple states and imperfect detection. Ecology 90:823-835.

Royle, J. A. 2004. N-mixture models for estimating population size from spatially replicated counts. Biometrics 60:108-115.

Seasholes, B. 2013. The endangered species act at 40: species profiles. Bald Eagle Species Profile. Reason Foundation. <http://reason.org/news/show/1013680.html>. Accessed 6 November 2016.

Thompson, C. M., P. E. Nye, G. A. Schmidt, and D. K. Garcelon. 2005. Foraging ecology of bald eagles in a freshwater tidal system. The Journal of Wildlife Management 69:609617.

Virginia Institute of Marine Science (VIMS). 2004. ChesMMAP bottom salinity. <http://www.arcgis.com/apps/Viewer/index.html?appid=8897fdb6714d44cc903e75b561 4709a9>. Accessed 13 October 2013. 
Watts, B. D., A. C. Markham, and M. A. Byrd. 2006. Salinity and population parameters of bald eagles (Haliaeetus leucocephalus) in the lower Chesapeake Bay. The Auk 123:393-404.

Watts, B. D., G. D. Therres, and M. A. Byrd. 2007. Status, distribution, and the future of bald eagles in the Chesapeake Bay area. Waterbirds 30(special publication):25-38.

White, G. C., and K. P. Burnham. 1999. Program MARK: Survival estimation from populations of marked animals. Bird Study 46(Supplement):120-138. 


\section{FIGURE CAPTIONS}

Figure 1. Map showing the location of the primary study area within the Chesapeake Bay region of Virginia, USA, where bald eagles were observed and counted (study period 2006-2012). Map also shows locations of bald eagle observations (counts) within the study area (dark grey dots).

Figure 2. Map showing the salinity class breakdown covering the study area within the Chesapeake Bay region of Virginia, USA. 


\section{TABLES}

Table 1: The number of surveys conducted along the James, Rappahannock, York, and Potomac Rivers from 2006 to 2012 in the Chesapeake Bay. 'Entire River' is a reference to if the survey was conducted all the way to the mouth of the Bay (Y) or only focused on the inland areas (N). 'Aerial' references whether the survey was conducted by air (Y) or by boat $(\mathrm{N})$.

\begin{tabular}{|c|c|c|c|c|}
\hline River & Year & No. Surveys & Entire River $(\mathrm{Y} / \mathrm{N})$ & Aerial (Y/N) \\
\hline \multirow[t]{7}{*}{ James } & 2006 & 2 & N-Close to mouth & $\mathrm{N}$ \\
\hline & 2007 & 2 & $\mathrm{Y}$ & Y \\
\hline & 2008 & 3 & $\mathrm{~N}$ & Y \\
\hline & 2009 & 1 & Y & $\mathrm{Y}$ \\
\hline & 2010 & 1 & $\mathrm{Y}$ & Y \\
\hline & 2011 & 3 & $\mathrm{~N}$ & $\mathrm{~N}$ \\
\hline & 2012 & 2 & $\mathrm{~N}$ & $\mathrm{~N}$ \\
\hline \multirow[t]{4}{*}{ York } & 2006 & 2 & $\mathrm{~N}$ (tributaries) & $\mathrm{N}$ \\
\hline & 2007 & 2 & $\mathrm{~N}$ & Y \\
\hline & 2008 & 2 & $\mathrm{~N}$ & Y \\
\hline & 2009 & 1 & $\mathrm{~N}$ & $\mathrm{Y}$ \\
\hline \multirow[t]{9}{*}{ Rappahannock } & 2006 & 2 & $\mathrm{~N}$ & $\mathrm{~N}$ \\
\hline & 2007 & 2 & $\mathrm{~N}$ & Y \\
\hline & & 7 & $\mathrm{~N}$ & $\mathrm{~N}$ \\
\hline & 2008 & 1 & $\mathrm{~N}$ & Y \\
\hline & & 5 & $\mathrm{~N}$ & $\mathrm{~N}$ \\
\hline & 2009 & 1 & $\mathrm{Y}$ & $\mathrm{Y}$ \\
\hline & 2010 & 1 & $\mathrm{Y}$ & $\mathrm{Y}$ \\
\hline & 2011 & 2 & $\mathrm{~N}$ & $\mathrm{~N}$ \\
\hline & 2012 & 3 & $\mathrm{~N}$ & $\mathrm{~N}$ \\
\hline \multirow[t]{8}{*}{ Potomac } & 2006 & 8 & $\mathrm{~N}$ & $\mathrm{~N}$ \\
\hline & 2007 & 2 & $\mathrm{~N}$ & $\mathrm{Y}$ \\
\hline & & 9 & $\mathrm{~N}$ & $\mathrm{~N}$ \\
\hline & 2008 & 2 & $\mathrm{~N}$ & Y \\
\hline & & 4 & $\mathrm{~N}$ & $\mathrm{~N}$ \\
\hline & 2009 & 1 & $\mathrm{Y}$ & Y \\
\hline & 2010 & 1 & $\mathrm{Y}$ & Y \\
\hline & 2011 & 1 & $\mathrm{~N}$ & $\mathrm{~N}$ \\
\hline Nanticoke, MD & 2007 & 1 & $\mathrm{Y}$ & $\mathrm{Y}$ \\
\hline Pocomoke & 2007 & 1 & Y & $\mathrm{Y}$ \\
\hline
\end{tabular}


Table 2. Table showing the model set with the 7 individual models that were created to test for the effects of land cover and salinity on bald eagle density in the Virginia region of the Chesapeake Bay (from 2006 to 2012).

\begin{tabular}{ll}
\hline Model Name & Mean population size and individual detection probability of bald eagles \\
\hline Terrestrial Land Cover & Developed, Wetlands, Canopy cover, Open \\
Salinity & Tidal, Oligohaline, Mesohaline \\
Habitat & Tidal, Oligohaline, Mesohaline, Developed, Wetlands, Canopy, Open \\
Canopy & Deciduous, Evergreen, Mixed forest \\
Wetlands & Wetlands \\
Anthropogenic & Developed \\
Intercept & None \\
\hline
\end{tabular}


Table 3. Table showing the summary statistics from summer datasets from 2006 to 2012 in the Chesapeake Bay, Virginia. Values calculated include the overall average number of eagles per river unit and survey and the average number of eagles seen per river unit (Avg./Ut.) and per survey (Avg./Survey) based on different salinity and land use values. Values include their corresponding standard errors (SE).

\begin{tabular}{lcccc}
\hline VALUE & Avg./Ut. & SE & Avg./Survey & SE \\
\hline Overall & 36.690 & 2.226 & 1023.310 & 11.763 \\
Tidal Fresh Water & 61.968 & 4.589 & 538.483 & 13.528 \\
Oligohaline Water & 42.700 & 4.233 & 363.690 & 12.353 \\
Mesohaline Water & 12.014 & 2.282 & 122.621 & 7.290 \\
Polyhaline Water & 57.667 & 22.965 & 29.828 & 16.516 \\
Developed Land & 11.660 & 3.381 & 20.103 & 4.440 \\
Wetlands & 47.538 & 6.234 & 173.759 & 11.919 \\
Cultivated Cropland & 57.548 & 6.657 & 250.034 & 13.876 \\
Open Lands & 32.664 & 3.793 & 261.310 & 10.729 \\
Deciduous Cover & 37.885 & 5.755 & 215.552 & 13.729 \\
Evergreen Cover & 21.944 & 8.198 & 27.241 & 9.134 \\
Mixed Cover & 5.500 & 1.565 & 1.138 & 0.712 \\
Combined Canopy & 34.388 & 2.989 & 540.724 & 11.854 \\
\hline
\end{tabular}


Table 4. Model estimates from the null (intercept) model. Estimates are from bald eagles in the Chesapeake Bay (2006 to 2012). Both real and beta estimates are of the individual detection probability for both adult and juvenile bald eagles and site-specific mean population sizes of bald eagles by age class. Derived estimates are of site-specific bald eagle occupancy by age and average detection rates of each age class. Standard errors (SE) and confidence intervals are listed for each parameter.

\begin{tabular}{lccc}
\hline Parameter & Estimate & SE & Confidence Interval \\
\hline Beta Estimates & & & \\
Individual Detection Probability of Adults & -346.859 & 0.000 & -346.859 to -346.859 \\
Individual Detection Probability of Juveniles & -307.961 & 0.000 & -307.961 to -307.961 \\
Mean Population Size of Adults & 76.393 & 0.000 & 76.393 to 76.393 \\
Mean Population Size of Juveniles & 71.883 & 0.000 & 71.883 to 71.883 \\
Real Estimates & & & \\
Individual Detection Probability of Adults & $<0.001$ & 0.000 & $<0.001$ to $<0.001$ \\
Individual Detection Probability of Juveniles & $<0.001$ & 0.000 & $<0.001$ to $<0.001$ \\
Mean Population Size of Adults & $1.654 \times 10^{31}$ & 0.000 & $1.654 \times 10^{31}$ to $1.654 \times 10^{31}$ \\
Mean Population Size of Juveniles & $1.503 \times 10^{33}$ & 0.000 & $1.503 \times 10^{33}$ to $1.503 \times 10^{33}$ \\
Derived Estimates & & & \\
Occupancy of Adults & 1.00 & 0.00 & 1.000 to 1.000 \\
Occupancy of Juveniles & 1.00 & 0.00 & 1.000 to 1.000 \\
Average Detection Probability of Adults & Not a Number & 0.00 & N/A \\
Average Detection Probability of Juveniles & Not a Number & 0.00 & N/A \\
\hline
\end{tabular}




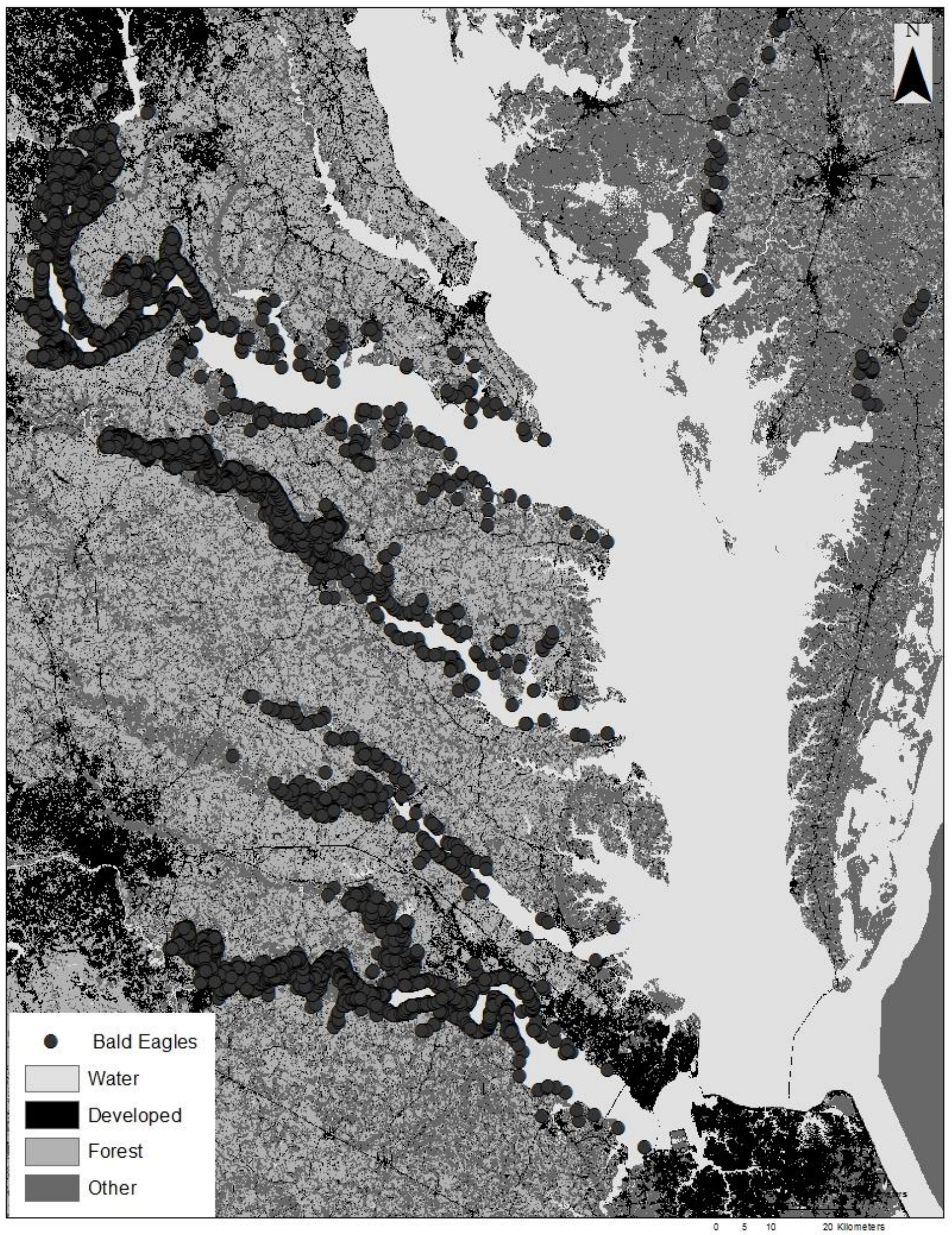




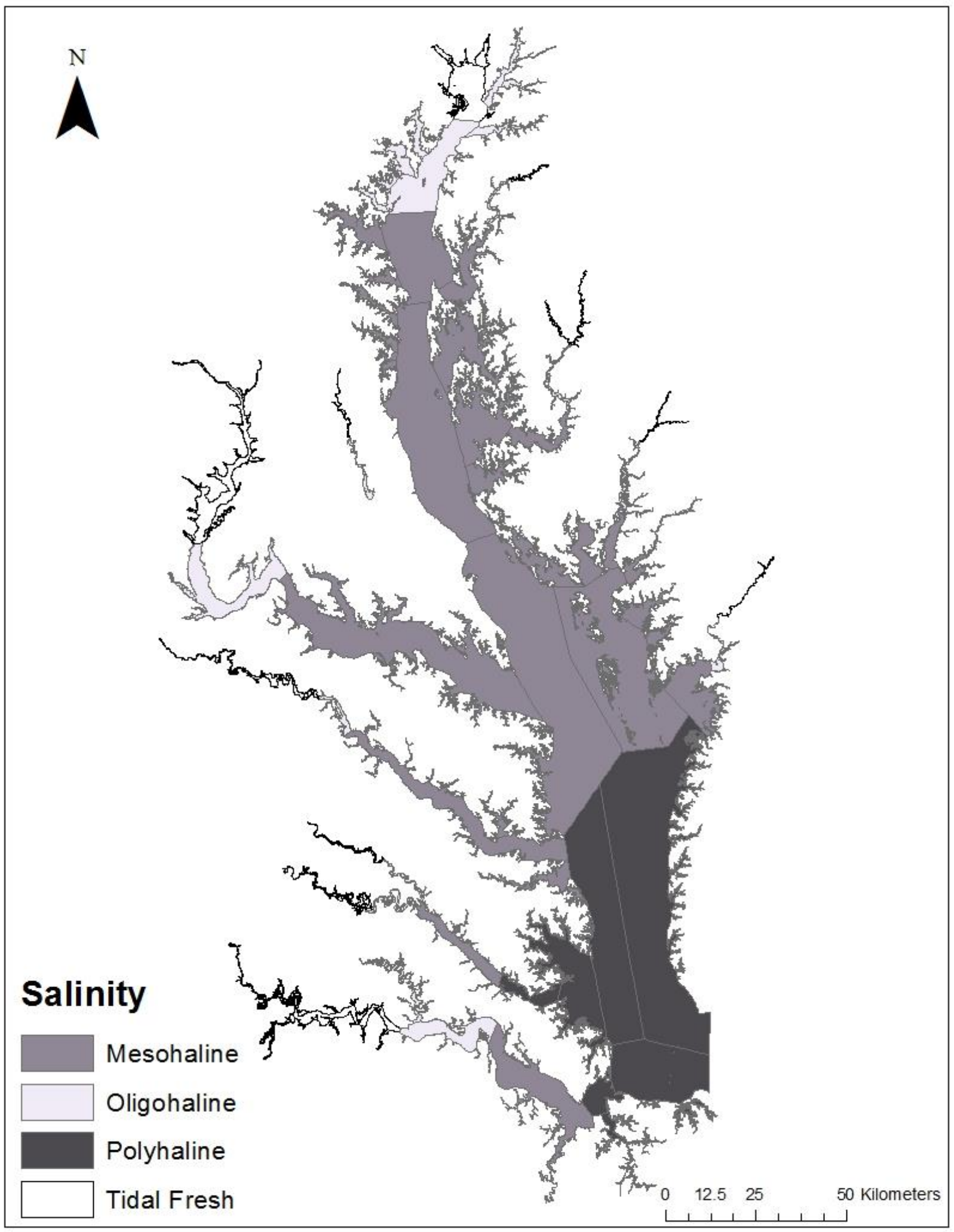

